\title{
LAS VIDAS DE MARÍA EN EL ÁMBITO PENINSULAR PRETRIDENTINO
}

\author{
(9) (1) \\ CARme Arronis Llopis ${ }^{1}$ \\ Universitat d'Alacant \\ FERNANDO BAÑos VALLEjo \\ Universidad de Oviedo
}

\section{Resumen}

Este estudio es un índice descriptivo y una tipología de las vitae Mariae escritas en distintas lenguas de la Península antes de 1559, fecha del Índice de libros prohibidos de Valdés. Reunimos, corregimos y completamos la información disponible actualmente sobre las primeras producciones peninsulares de este género. Proponemos además una clasificación que permite apreciar la génesis y desarrollo de una lectura cuyo éxito confluyó con el de la literatura hagiográfica y las vitae Christi.

Palabras clave: vida de María, literatura mariana, hagiografía, vitae Christi, género literario, traducción de literatura religiosa y reescritura.

\begin{abstract}
This study is a descriptive index and a typology of the vitae Mariae written in different languages of Iberia before 1559, the date of the Index of Prohibited Books by Valdés. We collect, correct and complete information currently available on the first Iberian productions of this genre. We also propose a classification that allows us to appreciate the genesis and development of a reading whose success came together with the success of hagiographic literature and vitae Christi.

Key words: life of Mary, Marian literature, hagiography, vitae Christi, literary genre, translation of religious literature and rewriting.
\end{abstract}

\section{INTRODUCCIÓN}

María es más que santa. En términos teológicos, no es una diosa, pero el culto que le corresponde a la Virgen está por encima del otorgado a los santos. Tres rangos de culto (latría, el de Cristo; hiperdulía, el de su madre; y dulía, el de los santos) han originado textos nacidos y recibidos con diferente consideración, aunque las analogías sean numerosas y sus génesis estén relacionadas ${ }^{2}$.

Acaso esta diferencia de culto explique que no existiera tradición medieval de vidas de María como tal. Su biografía no se difundía como un texto ejemplar, como la de los santos, pues las gracias obradas sobre ella en principio la hacían inimitable. Su culto

1 Universitat d'Alacant. Universidad de Oviedo. Correo: arronis@ua.es, banos@uniovi.es. Recibido 14-03-2014. Aceptado: 22-07-2014.

"Trabajo realizado en el marco del proyecto de investigación La literatura hagiográfica catalana entre el manuscrito y la imprenta (FFI2013-43927-P) del Ministerio de Economía y Competitividad."

2 Así se explica que nuestras monografías sobre las vidas de santos excluyan las vidas de Cristo y las vidas de María (Baños, 1989 y 2003). 
se vinculaba a la celebración de las festividades a lo largo del año litúrgico, en que se conmemoraban los sucesos de su vida; o a los relatos de milagros, que exaltaban su papel de mediadora y protectora de los fieles. Pero los movimientos espirituales de la baja Edad Media que se centran en la observación de la vida de Jesús, acaban llevando también a la contemplación de la vida de María, su madre.

No obstante, si en los siglos XIV y XV proliferan las vidas de Cristo, no florecen de igual modo las vidas de María exentas ${ }^{3}$. Habrá que esperar a bien entrado el siglo XVI, especialmente a partir del Concilio de Trento, para encontrar numerosas vidas de María que se difundían tanto de manera individual como compiladas en santorales, junto a las vidas de otros santos, y por tanto equiparándose de alguna manera a estos ${ }^{4}$. Este cambio significativo en la creación y recepción de los textos no es inmediato, sino que se va fraguando en obras de contenido mariológico, que cada vez muestran mayor interés por la narración ordenada de su biografía, hasta la configuración más o menos precisa de este género dentro de la literatura mariana.

Pese a que la producción peninsular de vidas de María es notable, el conocimiento que tenemos de esta clase de textos es escaso, está diseminado en estudios específicos o, por el contrario, perdido en rincones de repertorios muy voluminosos, por lo cual nos ha parecido conveniente ofrecer aquí un índice comentado de las primeras vidas de María que aparecieron en las distintas lenguas de la Península. Además, al reunir y confrontar la información disponible sobre estos textos, podremos percibir por vez primera las principales líneas de convergencia y divergencia entre relatos que, a priori, catalogaríamos como semejantes.

\section{DELIMITACIÓN DEL CORPUS}

Algunos autores se habían ocupado de la cuestión y habían agrupado textos de esta temática. Destacan especialmente los índices de Rodríguez (1967: 186-187), Simón Díaz (1985: 17-19) y sobre todo Bengoechea (1984), que suponen un punto de partida para este corpus. Sin embargo, es necesario revisar y completar estos trabajos $\left.{ }^{5}: 1\right)$ porque

3 Téngase en cuenta que las vidas de Cristo habitualmente contenían la de María.

4 Lo vemos por primera vez en las compilaciones de Alonso de Villegas (1578-1589) y Pedro de Ribadeneira (1599-1601), las reelaboraciones del Flos sanctorum llevadas a cabo bajo las preceptivas postridentinas que sustituyeron a las compilaciones medievales, hasta pocos años atrás todavía en las prensas. En ambas la vida de María aparece al inicio del compendio, aunque en las festividades correspondientes del ciclo litúrgico se sigue tratando de manera particular cada uno de sus misterios. Así, por ejemplo, lo indica Ribadeneira en su vida de María: "Esta es la vida de la sacratíssima Virgen nuestra Señora, sacada de graves autores, referida breve y sencillamente, dexando los inefables misterios que en ella se encierran para tratarlos más copiosamente los días de sus festividades, en que la santa Iglesia los celebra, como en sus proprios lugares se verá" (Ribadeneira, 1716[1599]: 163-164).

5 Para completar los índices hemos incluido los asientos de esta temática hallados en repertorios bibliográficos e historias de la literatura, como Gómez Redondo (2007 y 2012) o PhiloBiblon (http:/ / bancroft. berkeley.edu/philobiblon). 
son índices y no abordan el contenido de las obras, y sucede que los títulos no siempre son identificativos del contenido; 2) porque es necesario matizar algunas de estas inclusiones, y desestimar otras; 3) porque Rodríguez solo se ocupa de la Edad Media (y habla de textos mariológicos, no solo de vidas) ${ }^{6}$, Bengoechea solo de vidas de María impresas, y Simón Díaz solo de vidas impresas en la Edad Moderna.

Por nuestra parte, pretendemos que el corpus de vidas de María que aquí presentamos se asiente sobre criterios claros y precisos, tanto los externos a las obras como los internos.

En cuanto a los criterios externos, el cierre de nuestro corpus es cronológico: incluimos toda vida de María producida en la Península antes del 1559, independientemente de la lengua en que fue escrita (latín, castellano, catalán o gallego-portugués); de la forma, prosa o verso; o de la transmisión, manuscrita o impresa. Son los textos pioneros en saciar de alguna manera el interés de los fieles por la lectura de la vida de la Virgen. Cerramos con la fecha de 1559 por la aparición del Índice de Fernando de Valdés, ya que supuso un hito condicionante en la difusión de escritos, especialmente en los de materia religiosa ${ }^{7}$. Además, hasta mediados del siglo XVI, gran parte de los escritos devocionales que se siguen leyendo son medievales; de hecho, en las primeras décadas de la imprenta se estampan muchos textos del Medievo que satisfacen todavía los anhelos edificantes del público. Es decir, hay una continuidad, más que una ruptura, entre las obras bajomedievales y las impresas en la primera mitad del XVI, lo que no obsta para que en el paso a la imprenta y a la nueva centuria experimenten modificaciones que las adaptan al gusto de los lectores del momento.

Los criterios internos para fijar el corpus son más difíciles de establecer. Ocuparse de una clase de textos obliga a plantearse el concepto de género literario, pero como no cabe en las dimensiones de este artículo una reflexión preliminar sobre este asunto, remitimos a nuestros estudios (Baños, 1989: 17-26; y 2003: 9-15) sobre las vidas de santos como género literario. A la vista de que los tratados más recientes de genología

6 Rodríguez (1967: 186) incluye escritos marianos de “tipo devoto a base de cantar sus glorias, encomendarse a la protección de la Señora, narrar sus milagros o considerar su vida", por lo que nos interesarían solo estos últimos.

7 Pérez García (2006: 245-270) puso de relieve las consecuencias derivadas de la aparición del Índice en la transmisión de los libros de espiritualidad, tanto en el ámbito editorial como entre el público lector: "La publicación del Índice de Libros Prohibidos de 1559 repercutió de manera muy negativa en el negocio del libro, afectando tanto a los impresores como a los libreros y a los mercaderes de libros, es decir, a los factores financieros y técnicos que permitían la puesta en circulación de ediciones impresas de libros de espiritualidad" (266); "El tener o leer libros prohibidos, convertido en pecado grave, suponía incurrir en la pena de excomunión establecida en el Index de 1559, en sanciones económicas [...], en la consiguiente sospecha de herejía y en la imposibilidad de ser absuelto por otro confesor que no fuese el inquisidor correspondiente. Por estos medios se indujeron de manera efectiva actitudes individuales y sociales de autocensura, de prudencia, de miedo y de aceptación de la nueva realidad. El efecto en la sociología castellana de la lectura espiritual es indudable" (258). Las conclusiones para el caso de Cataluña y Valencia fueron similares, vid. Peña (1996) y Berger (1987). 
en nuestro ámbito siguen refiriéndose a las mismas autoridades ${ }^{8}$, parece que la base teórica y metodológica que adoptábamos para el estudio de las vidas de santos sigue siendo hoy válida para la caracterización de las vidas de María, y que no ha habido propuestas recientes que superen las de Todorov en relación con los géneros históricos, o Jauss respecto a los géneros como sistema en la literatura medieval.

Nuestro propósito es sentar las bases para la futura caracterización de un grupo de textos afines, apuntar los lugares comunes de las vidas de la María y sus variantes, de modo que no procede aquí la consideración más idealista o teórica de los géneros. Pero como ya manifestamos en los estudios antedichos, toda descripción de los géneros históricos o empíricos debe partir de una fundamentación teórica y metodológica que evite establecer clases arbitrariamente. Sigue pareciéndonos útil la restricción de Todorov: "llamar géneros únicamente a las clases de textos que han sido percibidas como tales en el curso de la historia" ${ }^{\prime}$. Es el caso de las vidas de María, así que podemos considerarlas un género literario, aunque la conciencia de tal clase sea entre autores y lectores más tardía y difusa que la noción de las vidas de santos. Esto se aprecia en el hecho de que solo tres de las ocho obras canónicas se titulan "vida".

En nuestra tipología de las vidas de santos proponíamos, para que la caracterización del género fuera lo más sólida posible, que el análisis no se limitase a un único criterio, ni métrico ni de ningún otro tipo, sino que atendiese a cuantos aspectos se muestren pertinentes, ya sean formales o de contenido, y relativos a la creación de las obras y a su recepción. Se podría aplicar ahora a las vidas de María lo que defendíamos para las vidas de santos: que dada la variedad de formas, empezando por el uso de la prosa y del verso, lo más operativo era atender a la reiteración de temas, estructuras y propósitos $^{10}$ :

1) Temática. Si atendemos a la idea de Todorov, la conciencia histórica de una clase de textos, debemos comenzar por la génesis de las vidas de María y la procedencia de su contenido. Fue uno más de los muchos géneros literarios que nacieron en la Edad Media, algunos de los cuales tienen como origen remoto la Biblia, y en concreto el Nuevo Testamento, o también, y significativamente para los géneros más literarios, los evangelios apócrifos. Es el caso de las vidas de María, cuyo contenido se remonta a una larga tradición que, en efecto, conecta con la Biblia y con los apócrifos, y también

8 A la compilación de Garrido Gallardo (1988) citada en esos libros nuestros, hemos sumado ahora la revisión de tratados como el de García Berrio y Huerta Calvo (1992), Rodríguez Pequeño (1995), y Arenas Cruz (1999).

9 Tzvetan Todorov, “El origen de los géneros”, en Garrido Gallardo (1988: 31-48, cit. 36).

10 Nos sigue pareciendo de referencia el estudio de la "tipología de las fuentes de la Edad Media occidental" emprendida en los años 70 por el Institut Interfacultaire d'Études Médiévales, bajo la dirección de Genicot (1972: 7). Pretendían establecer las claves de cada género como marco de referencia para la interpretación de los textos concretos. Tomaban como criterio básico de clasificación la finalidad del documento, y atendían a su realización en el contenido y en la forma, todo lo cual se adecua muy bien a la literatura hagiográfica. 
con sus reelaboraciones posteriores, con las exégesis patrísticas y con las narraciones de milagros; además, los episodios bíblicos y apócrifos sobre Jesús y María fueron difundidos y explicados constantemente en infinidad de ritos y textos durante toda la Edad Media. Si esto es así, debemos concluir que lo más específico de las vidas de la Virgen como género literario no es tanto el contenido como la estructura y la función.

2) Estructura. Paradójicamente, aunque las figuras centrales de los evangelios son Cristo y María, las vitae Christi y las vitae Mariae, concebidas como relatos literarios, son posteriores a las vidas de los santos y siguen algunas de sus pautas, como decíamos arriba. Las vidas de santos tienen su origen en las actas de los mártires escritas entre los siglos II al IV, y se desarrollan narrativamente en las modalidades de pasiones y de vidas desde el siglo $\mathrm{V}$, con componentes tomados del Nuevo Testamento que miran al modelo de Cristo, tales como el retiro, el interrogatorio, la tortura, la ejecución y los milagros. Esos elementos se van integrando en una estructura narrativa más ambiciosa, en cuanto que articula más claramente el proceso de santificación; empiezan a menudo por la infancia o incluso por el deseo de los padres de engendrar una criatura que pudieran ofrecer al servicio de Dios.

Si relacionamos las vidas de María con la idea de Jauss (1970: 79-99; y 1979: 181-229) sobre la modificación del horizonte de expectativa, en referencia a que las obras beben de la tradición genérica, pero también según los casos se apartan de lo puramente convencional, y pueden llegar a intervenir sobre las expectativas, diríamos que los biógrafos de María aprovechan la expectativa creada en el público durante siglos de difusión de vidas de santos, para exaltar las virtudes y capacidad intercesora y salvífica de María. Más adelante veremos ejemplos de comparación de las vidas de santos con la vida de María (1.6) y la de sus padres (3.1.2). Esa expectativa podría resumirse en un gusto hecho al relato de la infancia, formación, santificación y milagros. El orden cronológico-biográfico permitirá discriminar los relatos que son vidas de María de otros textos de devoción mariana, que históricamente se estructuraban siguiendo el orden litúrgico. Además, tendremos en cuenta la completitud, pues no parece adecuado darle la consideración de vida de María plena a un relato que sea muy parcial, que no presente la trayectoria biográfica general. Sin embargo, hay que notar que hasta en las que sí consideramos vidas de María, porque cuentan prácticamente toda su existencia por orden, suele faltar algún episodio aislado.

3) Función. Junto a los contenidos y la estructura, la función sería otro elemento esencial para la caracterización del género. También para este aspecto, como para el del contenido y la estructura, la consideración del título sería muy pertinente, pero no podemos guiarnos sin más por la rúbrica. En efecto, hay obras que son vidas de María y sin embargo no llevan ese título. Por otro lado, no pocos textos citados en las bibliografías como vidas de María no se ajustan a esa modalidad literaria (véase el listado de obras excluidas). La función a la que responden las vidas de la Virgen es la lectura 
edificante no litúrgica, especialmente para lectoras o para ámbitos femeninos, sean conventuales o nobiliarios; así lo indican con frecuencia las dedicatorias, aunque no por ello tenemos que descartar cualquier otro tipo de lector, claro está. Y la intención es captar el interés mediante un relato articulado (más ameno y sugestivo que un sermón o un tratado) y así promover la alabanza de María por sus excelencias y la imitación de su conducta, aunque la plenitud de sus virtudes sea inalcanzable para las mujeres. Teniendo esto en cuenta, los títulos nos sirven más bien para descartar, cuando identifican el texto como un sermón o tratado (donde el contenido es eminentemente doctrinal y los hechos biográficos quedan reducidos a alusiones), o como un texto lírico, más expresivo de la devoción, que narrativo.

Tales criterios internos pueden resumirse en que consideramos una vida de María todo texto de carácter narrativo que presenta una biografía ordenada de la Virgen, bien lo indique expresamente en el título o no, y que tiene la función de ser lectura piadosa en ámbito no litúrgico. La fijación del corpus según los criterios expuestos nos lleva a excluir de la consideración como vidas de María obras de carácter teológico, doctrinal, homilético, litúrgico o paralitúrgico y lírico-laudatorio citadas por Rodríguez (1967: 186-187), Bengoechea (1984) y Simón Díaz (1985: 17-19), y a añadir otras no tenidas en consideración por ellos.

Nos alejamos, por tanto, de los criterios flexibles de Bengoechea, que consideraba vidas:

las vidas propiamente dichas, cuya enunciación aparezca en el título de la obra; las vidas de la Virgen incluidas en santorales y mariales, en aquellos al tratar de las festividades de Nuestra Señora y en estos al reproducir sermones acerca de los misterios de la vida de María. En tercer lugar, anotamos también algunas obras que sin ser propiamente Vidas presentan algunos aspectos interesantes en relación con la existencia terrenal de Nuestra Señora. (Bengoechea, 1984: 560)

Nosotros entendemos que para valorar un texto como una vida ha de ser un relato ordenado cronológicamente y bastante completo (que más o menos trate toda su existencia y no uno o unos pocos episodios aislados) ${ }^{11}$. Tales condiciones a veces van expresamente rubricadas bajo el título de vida de María, pero no siempre. Constituyen la primera parte del índice descriptivo que aquí ofrecemos, con ocho obras.

Después se comentan dos obras perdidas, que consecuentemente no podemos incluir con seguridad en ninguno de los otros dos apartados.

La tercera parte son las obras que clasificamos problemáticamente como vidas, pues aunque presentan la vida terrenal de María en una narración, no parecen suficientemente completas, o la materia biográfica mariana queda diluida entre cuestiones doctrinales, o es mero complemento y marco de la de Cristo. En todo caso, son textos que por su afinidad con el género que tratamos merecen un análisis individualizado. Van clasificados en tres grupos: los relatos muy parciales, los de estructura atípica y las

11 En esto último, en la completitud, sí coincidimos con Bengoechea (1984: 560). 
partes marianas de las Vitae Christi.

Finalmente, quedarían excluidos y sin comentario (aunque recogidos en un listado al final con indicación de la referencia) los escritos que reproducen de manera fragmentaria o desordenada la biografía de la Virgen, como por ejemplo colecciones de sermones o los flores sanctorum que solo incluyen episodios de la vida de María vinculados a sus festividades litúrgicas, pues aunque sean textos de carácter mariológico y se ocupen de segmentos de su vida, entendemos que no funcionan como un relato biográfico. También quedarían excluidas obras lírico-laudatorias o tratados de teología mariana que no se centran en los episodios de su vida.

\section{CLASIFICACIÓN DE LAS VIDAS DE MARÍA}

El índice se presenta, entonces, con la siguiente estructura:

1. Vidas de María: el canon

2. Vidas de Jesús y María perdidas

3. Textos afines a las vidas de María

3.1. Vidas de María parciales

3.2. Vidas de María con estructura atípica

3.3. Vitae Christi que incluyen la Vida de María

En cada entrada se muestran, cuando sea pertinente, los siguientes campos de información:

Número

Título

Autor, traductor u obra anónima

Fecha de redacción o de traducción

Lengua

Manuscrito o edición

Referencia de índices anteriores

Comentario

\section{Vidas de María: el canon}

Relacionamos a continuación las vidas de María que muestran las características propias del género según queda descrito arriba. 


\section{1}

\section{Liber Mariae}

Autor: fray Juan Gil de Zamora

Fecha de redacción: segunda mitad del siglo XIII

Lengua: latín

Manuscrito: 9503 de la Biblioteca Nacional de España, ff. 1-195; ms.

110 de la Biblioteca de la Catedral de Burgo de Osma, ff. 1-229

Comentario: No puede ser casual que las dos obras que marcan el inicio de la tradición hispánica de las vidas de María (esta de Juan Gil y la de Brihuega, en el apartado de vidas perdidas) surjan en la corte de Alfonso $X$, que a su vez fue el más famoso cantor de la Virgen. Dicho sea al paso que también Berceo remató sus Milagros de Nuestra Señora ya en el reinado de Alfonso. En efecto, parece que no solo sus cantigas en gallego, sino además estas dos obras en latín habrían sido impulsadas por el rey Sabio. Es de notar que en la rúbrica del Oficio de la Virgen, del mismo Juan Gil y conservado a continuación en el mismo códice, el fraile franciscano afirma que lo compuso "ad preces et instantiam illustrisimi Aldefonsi regis Legionis et Castellae". Por otro lado, el rey Sabio fue objeto de una biografía escrita por el franciscano. En opinión de Fita, a quien debemos la primera descripción del contenido del Liber Mariae y la edición de cincuenta de sus milagros ${ }^{12}$, las obras de Juan Gil pudieron inspirar al rey poeta, o a la inversa. Hoy se piensa más bien que manejaron fuentes comunes, y que las cantigas alfonsinas son anteriores (vid. Bohdziewicz, 2012-2013: 178).

Es conocido que Juan Gil fue uno de los mayores polígrafos hispanomedievales, que escribió crónicas, biografías, tratados de ciencia natural, enciclopédicos, retóricos, religiosos, pero en lo que guarda más relación con nuestro tema, conviene precisar que el autor cita en el Liber Mariae otros textos hagiográficos no localizados, sobre san Pablo, Santiago y santo Tomás, y un Liber Ihesu ${ }^{13}$, que habría precedido al Liber Mariae. La sabiduría del fraile, visible en sus obras y acreditada por el título de doctor y por haber estudiado en París, donde debió de ser alumno del mismísimo san Buenaventura, lo llevaron a recibir del rey el encargo de la educación de Sancho, el príncipe heredero (vid. Bohdziewicz, 2012-2013: 169). No cabe duda de que su estancia en París le permitió profundizar en cuestiones teológicas como el inmaculismo (dedica una parte de su Liber Mariae a la Inmaculada Concepción), y plantearse su posición en las corrientes enfrentadas de la orden franciscana, que pudo ser cercana al espiritualismo de Raimundo de Geoffroi (vid. Ferrero Hernández, 2010).

12 Fita (1885a y 1885b). La edición integral del Liber Mariae la prepara Bohdziewicz, que ha publicado un estado de la cuestión (2012-2013).

13 Del Liber Jesu se conserva un ejemplar en la Biblioteca de Palacio (Madrid): ms. 957. 
Según se deduce de las palabras del franciscano, parece que el Liber Ihesu y el Liber Mariae fueron concebidos como dos partes de una misma obra, aunque hoy se conservan por separado: "Primus autem liber erit de Jhesu Nazareno filio summi Regis primogenito et heredis. Secundus intitulabitur Liber Virginis Mariae almiflue Matris eius. Titulus ergo Libri talis est: Liber Ihesu et Mariae" (Vílchez, 2007: 37).

Si atendemos al contenido del Liber Mariae, se puede cabalmente considerar una vida de María, aunque no se llame así1 ${ }^{14}$. Está estructurado en dieciocho capítulos, que se ocupan de los episodios de la biografía de María más directamente relacionados con las festividades litúrgicas y de algunas otras cuestiones doctrinales: profecías y prefiguraciones veterotestamentarias de la Virgen; la Inmaculada Concepción; la santificación que de María hicieron los doctores de la Iglesia, y termina ponderando la debida a san Ildefonso (hasta aquí, folio 23, es todo puramente doctrinal); la Natividad de María; la Anunciación; la Natividad de Jesús; la Purificación de María y la presentación del Hijo en el templo; la Huida a Egipto; la pérdida del Hijo en el templo; la compasión de María en la Pasión; Jesús agonizante encomienda a su madre a Juan; el trato de María con los apóstoles tras la resurrección y Ascensión de Cristo; la dormición de María; la Asunción; exhortación a vírgenes y viudas para la imitación de María; y meditaciones y oraciones sobre la Virgen y Jesús ${ }^{15}$. Se incorporan ochenta y ocho milagros marianos: veintiséis se intercalan en los episodios, y los restantes se agrupan en el capítulo XVI. Juan Gil se ocupa de las festividades litúrgicas relacionadas con María, pero las reordena según el orden cronológico, con lo que compone una verdadera vida de María. Bebe de la tradición culta de los comentarios patrísticos que explican los pasajes canónicos y apócrifos, pero aligera la carga doctrinal, y por otro lado añade el ingrediente más popular: los milagros.

Es de destacar que si por un lado Juan Gil no desligó completamente la vida de María de la de Jesús, puesto que quiso que ambos libros fueran unidos, sí que llegó en la separación más allá que otros biógrafos de María, que no pasan de ocuparse de su vida como parte de la de Jesús, como ocurre en muchas de las Vitae Christi.

Salvo las versiones romances de la obra de Brihuega, que trataremos en el apartado de obras perdidas, no parece que tras el reinado de Alfonso X haya continuidad en la producción de nuevas vidas de María, de manera que la siguiente será la de Joan Roís de Corella, y eso nos lleva en un salto de dos siglos a la Valencia de finales del XV. Con frecuencia se ha subrayado la proliferación de obras devocionales en esta área en dicho período, especialmente de vidas de santos y vidas de Cristo; asimismo, la

14 Juan Gil lo llama Libro, apelativo que tiene precedentes en la literatura mariana; por ejemplo, una reelaboración de la época carolingia del evangelio apócrifo de Pseudo-Mateo, se difundió con el título de Liber o Libellus Nativitate Mariae (vid. la edición y el comentario del texto en Beyers, 1997).

15 Esta estructuración del contenido por capítulos será la habitual, mutatis mutandis, en la mayoría de las obras sobre la vida de la Virgen. 
devoción mariana siempre tuvo notables valedores en los territorios de la Corona de Aragón, sobre todo en relación a la tesis del inmaculismo, que fue promovida tanto por las proclamas de sus gobernantes como por la pluma de eclesiásticos y literatos ${ }^{16}$. No sorprende, pues, que la ciudad de Valencia entre finales del siglo XV y principios del XVI fuese el contexto literario y espiritual idóneo para la creación de las primeras obras en catalán dedicadas a la vida de María, tanto en prosa como en verso.

Es el mismo contexto en que encontramos una burguesía letrada dedicada a la producción y consumo de obras tanto lúdicas como devotas, y a la celebración colectiva de la actividad literaria, a menudo materializada en forma de justas poéticas. Entre el último tercio del siglo XV y el primero del XVI se organizan numerosos certámenes dedicados a la glorificación de la Virgen María ${ }^{17}$. Sin embargo, la mayor parte de estas composiciones es de temática laudatoria o apologética, especialmente en relación al dogma del inmaculismo, según lo dicho ${ }^{18}$.

No obstante, también encontramos algunas composiciones poéticas que se centran en la narración de la vida de María. El caso más representativo es el de la Vida de la sacratissima verge Maria del valenciano Joan Roís de Corella.

\footnotetext{
16 Ferrando (1983) nos proporciona diversos ejemplos. Respecto a los gobernantes, recordemos la pragmática de Joan I (1394) a favor del dogma, el edicto del gobernador de Valencia, Eiximén Pereç de Corella (1429-1448) instando a la celebración de la festividad de la Inmaculada Concepción de María, o los esfuerzos del obispo de Elna, Joan Margarit, que promovió la inclusión de la creencia inmaculista en las Constitucions de Catalunya, aprobadas por las Cortes catalanas de Barcelona en 1456 (379-380). En relación con los autores religiosos, uno de los principales defensores del dogma fue ya Ramon Llull, quien tuvo un notable peso en la cultura catalana posterior. Otros ejemplos representativos fueron el franciscano Francesc Eiximenis e incluso el dominico Vicent Ferrer, en contra de las proclamas antiinmaculistas de su propia orden (71-72). Entre los literatos, no dudaron en pronunciarse en sus obras a favor del dogma inmaculista prácticamente todos los nombres destacados de la Valencia de finales del XV, como Joanot Martorell, Jaume Roig, Joan Roís de Corella, Isabel de Villena, Bernat Fenollar, Pere Vilaspinosa o Miquel Peres (380).
}

17 De las catorce justas poéticas que se celebraron en dicho período en la ciudad, diez están dedicadas a ensalzar advocaciones o festividades de la Virgen María (Ferrando, 1983: 65-865).

18 En honor de la Inmaculada Concepción se celebraron certámenes en 1486, 1487, 1488, y 1532. Los tres primeros fueron convocados por el presbítero Ferrando Díeç, y en ellos se aprecia un marcado tono apologético, seguramente alentado por la recién establecida Inquisición Española (1484), y por el estado de la polémica en torno al dogma, secundado por las proclamas del papa Sixto IV (en 1476 y 1484) (Ferrando, 1983: 381-382). 


\section{2}

Vida de la sacratíssima verge Maria

Autor: Joan Roís de Corella

Fecha de redacción: 1474 terminus ante quem

Lengua: catalán

Manuscrito e impresos: De la primera versión, la Vida de la sacratíssima verge Maria, mare de Déu, senyora nostra, en cobles de rims strams, se conserva un testimonio manuscrito, copiado en el Cançoner de Maians (Biblioteca Històrica de la Universitat de València, ff. 130r-133v), y dos testimonios impresos, pues la oración se editó al final del primer volumen de Lo Cartoixà, traducción que realizó Corella de la Vita Cristi de Ludolfo de Sajonia (Valencia, 1496; Barcelona, 1518) (vid. edición de Miquel i Planas, 1913: 403-405). La segunda versión, Resposta de mestre Corella, ab rims estrams, en laor de la Verge Maria, tirant a la joia, se editó en el volumen Trobes en lahors de la Verge Maria (Valencia, 1474), vid. edición de Sanchis Guarner (1979). Véase una comparación de las dos versiones en Martos (2013)

Comentario: De la obra se conservan dos versiones, pues Corella modificó una composición anterior para presentarla al certamen celebrado en Lahors de la Verge Maria (Valencia, 1474), de modo que redujo sus 184 versos iniciales a solo 66 para adecuarlo a los cánones de la justa poética. De hecho, no sabemos si este origen previo es la razón que explicaría que de las cuarenta y seis composiciones publicadas en el volumen de les Trobes en lahors de la Verge Maria, editado tras la celebración del certamen, solo la de Corella se centre en la temática biográfica, y se diferencie así del resto de los poemas congregados, que en su mayoría consisten en letanías laudatorias.

La vida de la sacratísima verge Maria, en su versión extensa, se compone de 23 estrofas de ocho versos blancos. En ella Corella repasa de manera ordenada los acontecimientos esenciales de la vida de la Virgen, desde la Concepción a la Asunción, normalmente ocupándose de uno por cada estrofa, y los adereza con metáforas e imágenes de procedencia bíblica. La única omisión destacable que observamos concierne a los esponsales de María y José, pues la figura del santo no se menciona en ningún punto de la composición, ni siquiera en la huida a Egipto, huida que, según el Evangelio, fue revelada a José en un sueño ${ }^{19}$.

La composición de Corella supone casi una excepción en la abundante poesía ma-

19 "Per lo desert fogint-lo en Egipte, / ab tal dolor, que nostre cor vol rompre / veure-us fogir portant Déu en los braços. / De quand fa Déu, clos sagellat registre, / ab quin recel lo portàs per les roques, / ab fam, ab set, passant camí tan aspre, / dormint la nit en les humides silves! / Fins que vingués en hun loch, prop lo Cayre, / hon descansàs, passant la vida pobra, / filant, cosint, perquè tingués què viure / vostre Fill Déu, qui tot lo món governa" (vv. 95-104, vid. Miquel i Planas, 1913: 396-397). 
riológica coetánea, de carácter eminentemente laudatorio o teológico ${ }^{20}$. También resulta novedoso el rótulo de "vida", pues se trata del primer testimonio hispánico de tal denominación para referirse a un relato sobre la Virgen; de este modo por primera vez se explicita la naturaleza biográfica de la narración. Cabe recordar que Corella fue autor asimismo de distintas hagiografías en prosa, como son la Història de Joseph, fill del gran patriarca Jacob, La vida de la gloriosa santa Anna, y La història de la gloriosa santa Magdalena, así que podemos pensar que Corella estaba familiarizado con la estructura y el propósito de las vidas de santos. Además, tradujo al catalán la Vita Christi del Cartujano, Lo Cartoixà (de la que nos ocuparemos más adelante, 3.3.5), donde también se resume la vida de María como marco a la de Cristo, otro acercamiento a la misma temática.

1.3
Triunphes de Nostra Dona
Autor: Jaume d'Olesa
Fecha de redacción: ca. 1488
Lengua: catalán
Ejemplar: Real Academia de la Historia, Cortes 9/2161, ff. 130-13

Comentario: Esta composición, como las dos siguientes, parecen estar enmarcadas en la celebración de un certamen valenciano en honor de los Triunfos de Nuestra Seño$r a$, la única referencia del cual aparece precisamente en la rúbrica de este poema del mallorquín Jaume d'Olesa ${ }^{21}$ : Triumphes de Nostra Dona en cobles capdenals biocades, per lo demirable enginy Jaume d'Aulesa, ciutedà, compostes e trameses en València per la joya [que] era allí mesa als qui mils hi digués ${ }^{22}$. Ferrando (1983: 361-362) ha relacionado la celebración de este certamen con la Guerra de Granada (1481-1492), pues en la conclusión del poema encontramos una referencia explícita al conflicto ${ }^{23}$, o incluso con la visita de los Reyes Católicos a la ciudad de Valencia en 1488.

Parece, pues, que la temática biográfica en esta ocasión venía determinada por el cartel de la justa, ya que para abordar los triunfos de María necesariamente se han de recordar los episodios más importantes de su vida. La composición, de veinte estrofas de nueve versos, precedida de una invocación en latín y cerrada por una "Tornada"

20 De hecho, el propio Corella es autor de otras dos composiciones mariológicas, la Oración a la senyora Nostra tenint son fill Déu Jesús devallat de la creu, planto editado como colofón al Quart de Lo Cartoixà (editado en Valencia, dos veces en 1495 y otra en 1513) y también junto a Lo passi en cobles de Bernat Fenollar (Valencia, 1493 y 1518); y el hoy perdido Tractat de la Concepció de la sacratíssima Verge Maria, Mare de Déu (Valencia, ca. 1493).

21 Jaume d'Olesa, noble erudito mallorquín, era hijo del embajador de Fernando el Católico en Nápoles, Rafael d'Olesa.

22 Vid. la edición del texto en Ferrando (1983: 371-377).

23 “Mare de Déu, qui ls superbos deposa, / nostre rey sanct haja son cor complit: / que 1 moro rey qui $n$ Granada reposa / sie expel lit/ y Jesu Crist hi sia beneït" (Ferrando, 1983: 361). 
y una "Endressa", loa y evoca de manera cronológica los principales momentos de la vida de María, recogidos en los evangelios, los apócrifos, e incluso en la tradición popular. Pero con frecuencia se trata de meras referencias a los episodios, en ocasiones incluso veladas ${ }^{24}$, por lo que la composición carece de la índole narrativa de la Vida de la sacratísima verge Maria de Corella. Los versos anafóricos introducidos con frecuencia por el autor ("Vós triünphau...") aportan al texto cierto carácter de letanía, que diluye cualquier intención por narrar los acontecimientos. Sorprende, además, el salto abrupto entre la estrofa 14 y 15, pues pasa de ocuparse de la Presentación del niño Jesús en el templo a la celebración de la Última Cena. La composición, por tanto, trata de la existencia terrenal de la Virgen, pero no desarrolla su relato.

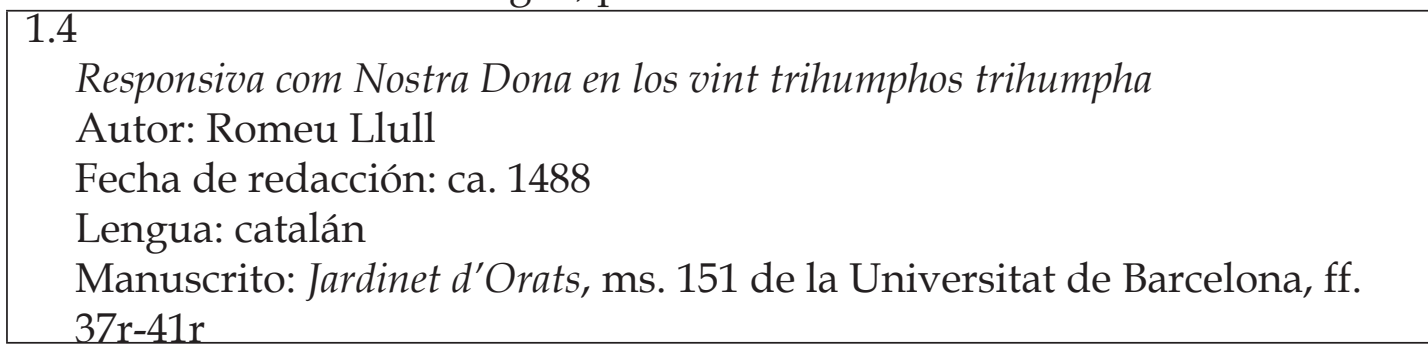

Comentario: La similitud del título y de la estructura de este poema con los del anterior parece indicar que el barcelonés Romeu Llull participó en el mismo certamen en Loor de los Triunfos de María, del que hoy no tenemos más evidencia que las alusiones en las rúbricas de estas composiciones (Ferrando, 1983: 363). El poema se conserva copiado en el manuscrito conocido como el Jardinet d'Orats, donde se compilan distintas obras de temática devocional y piadosa.

También este poema se compone de veinte estrofas, esta vez de diez versos ${ }^{25}$, en que se loan los distintos triunfos de la Virgen, es decir, los principales episodios de su vida, y se cierra con una endereza a la "Gloriosa Mare de Déu". La distribución de las estrofas por la temática es idéntica a la del poema anterior, pero en esta ocasión, la ausencia de recursos anafóricos favorece la fluencia narrativa.

1.5
Obra en loor de las XX excelencias de Nuestra Señora
Autor: Juan Tallante
Fecha de redacción: ca. 1488
Lengua: castellano

Comentario: El título de la composición y la participación de Tallante en otros certá-

\footnotetext{
24 Vemos, por ejemplo, la sutil referencia con que se alude a la visitación de santa Isabel: “Vós triünphau, car puys fós instruïda / per l'àngel sanct que 1 vostre cors prenys era, / anàs allí ab amor vertadera, hon demostràs humilitat complida".

25 Sin embargo la tercera estrofa "De la sua Desponsació ab Joseph", solo tiene nueve versos, quizá por error de copista.
} 
menes valencianos en la misma época ${ }^{26}$ parecen indicar, como ya hizo notar Ferrando (1983: 362-363), que también este poema, con el que se abre el Cancionero General de Hernando del Castillo (1511), fue escrito para concursar en el certamen mariano ya referido en Loor de los Triunfos de María.

Como las anteriores, esta obrita, de también veinte estrofas, ahora de ocho versos, recuerda brevemente veinte episodios de la vida de María ordenados cronológicamen$t^{27}$. También en esta ocasión encontramos el salto abrupto entre la estrofa 14 y 15, pues tras aludir a la Presentación del niño Jesús en el templo, pasa a la consagración celebrada en la Última Cena. Quizá la temática para este certamen había sido especialmente acotada para la convocatoria, de manera que la narración de los episodios se supeditase a un esquema previo.

Estas tres últimas composiciones, por tanto, no parecen ser fruto de la voluntad espontánea de los poetas por narrar la vida de María, sino que han sido motivadas por la temática propuesta para el certamen. No obstante, el tema de la justa no deja de ser una evidencia del interés existente por celebrar los episodios biográficos más destacados de la existencia terrenal de la Virgen.

\section{6}

Vida de la sacratíssima verge Maria

Autor: Miquel Peres

Fecha de redacción: 1494

Lengua: catalán; y traducción anónima al castellano

Edición: Valencia, N. Spindeler, 1494; ejemplar: Biblioteca Històrica de la Universitat de València, CF/5. Traducción castellana: Sevilla,

J. Cromberger, 1516; ejemplar: Biblioteca Pública de Évora, 5388-A.

Vid. Arronis (2012a, 59-61; 86-88)

Referencia de índices anteriores: Bengoechea $\mathrm{n}^{\circ} 3$

Comentario: Esta obra en prosa del notario valenciano Miquel Peres es probablemente la más representativa del género en el marco temporal que acotamos. Es fruto del mismo momento cultural y espiritual que los poemas descritos arriba. La burguesía valenciana de finales del XV no solo participa en justas poéticas, sino que patrocina, consume e incluso produce obras devocionales de distinto tipo.

El caso de Miquel Peres es especialmente representativo. Además de concurrir a certámenes literarios marianos ${ }^{28}$, hizo versiones en catalán de distintas obras latinas

26 En 1486 participó en la justa en Lahors de la Inmaculada Concepció, y su composición es la única pieza castellana del certamen.

27 Vid. la edición del texto en González Cuenca (2004: 225-234).

28 Por ejemplo en la conocida justa en Lahors de la Verge Maria de 1474, donde también participó Roís de Corella, y probablemente en un certamen en latín en honor de la Inmaculada Concepción de 1488, 
de temática devocional y hagiográfica, glosándolas y amplificándolas en un estilo de prosa artificiosa característico ${ }^{29}$. La Vida de la sacratíssima Verge Maria es su obra más original. A partir de la fusión de distintas fuentes ${ }^{30}$, Peres construye una exhaustiva vida de María ordenada en treinta capítulos. Además, cada capítulo se cierra con una oración rogatoria y, a continuación, con la narración de un milagro obrado por la Virgen que se relaciona temáticamente con el episodio expuesto ${ }^{31}$. Parece que el texto está especialmente influenciado por el modelo hagiográfico, donde se conjugan vida y milagros de los santos, y por el modelo de las vitae Christi (en particular la del cartujano Ludolfo de Sajonia), donde se alternan descripciones minuciosas de las escenas con las exégesis de su significado ${ }^{32}$.

En la Vida de la sacratíssima verge Maria se narran tanto los episodios de procedencia apócrifa, por ejemplo los acontecimientos de su infancia (Inmaculada Concepción, vida en el templo, matrimonio con José) o sus últimos años (vida tras la Ascensión de Jesús, Dormición y Asunción), como los episodios de las festividades marianas y crísticas (Anunciación, Visitación de Isabel, Natividad de Jesús, Presentación en el templo, Purificación de la Virgen, Adoración de los reyes, etc.). Un amplio grupo de capítulos se ocupa de los acontecimientos relacionados con la pasión, muerte y resurrección de Jesucristo, aunque el foco de atención siempre recae sobre la figura de María. De hecho, uno de los rasgos más característicos de la obra es, precisamente, el absoluto protagonismo de María en todos los sucesos narrados. Peres solo incorpora episodios en los que María, o bien es la protagonista principal de los hechos, o bien un testigo privilegiado, de manera que la lectura nos muestra sus sentimientos ante los acontecimientos a través de la narración omnisciente o mediante monólogos interiores ${ }^{33}$. De esta manera enfatiza el protagonismo de María como madre, como evangelizadora y como modelo ejemplar de cristiandad.

aunque esta composición no se ha conservado (vid. Ferrando, 1983: 557).

29 Su versión libre de la Imitatio Christi, la obra más representativa de la renovación espiritual acometida en los Países Bajos, fue la primera traducción en romance que se llevó a la imprenta (Barcelona, 1482, P. Posa). También versionó la Vida de sancta Catherina de Sena, ampliando la versión del Chronicon de Antonino de Florencia (Valencia, 1499, C. Cofman), y la Vida de sant Vicent Ferrer (Valencia, 1510, J. Jofré) a partir de distintas fuentes (vid. Arronis, 2007: 43-49).

30 Parece apreciarse especialmente el influjo de las Meditationes vitae Christi del Pseudo-Buenaventura y de la Vita Christi del Cartujano (Arronis, 2012a: 205-231).

31 Sobre este particular procedimiento vid. Arronis (2010).

32 Vid. la edición del texto en Arronis (2012a).

33 “ $\mathrm{O}$, fill e senyor meu, creador de les fonts y de totes les aygües! De gran e amarga tristor la mia trista ànima se cobre mirant que vós, que donau past y a beure a tots los animals de la mar y de la terra, demaneu a beure e no y ha qui us ne done; que yo, en estament de tan gran pobretat só costituhida, que alguna cosa temporal nom trobe acostumat ésser riqua, puix a vós, tresor de preu infinit, yo possehia. $\mathrm{Y}$ ara us veig axí apartat de mi que, morint ab tan estrema set, no us puch donar alguna freda aygua a beure, ni si les salades aigües que de les fonts dels meus plorants ulls decórren volia donar-vos, no porien atényer les mies mans per la gran altitut de la creu a la vostra preciosa boca" (Peres, 77v). 
La obra de Peres constituye un ejemplo de fusión de doctrina y devoción popular. Los contenidos teológicos de tradición escolástica se alternan con descripciones emotivas características de la nueva espiritualidad contemplativa, e incluso con oraciones y milagros que reflejan la vertiente más popular del culto mariano. Este equilibrio entre tradición, doctrina y renovación espiritual es una de las características de la prosa de Miquel Peres, por lo que Ferrando (1993: 166) concluye que “a pesar de su medievalismo, la hagiografía de Miquel Peres contiene dos aspectos relativamente innovadores: la influencia de la espiritualidad centrada en la meditación y la voluntad estilística".

La Vida de la sacratíssima verge Maria, por tanto, representa el paradigma del género de las vitae Mariae por su completitud y su ordenación cronológica, pero también por su función. Peres compuso el texto con la intención explícita de ofrecer la vida de María como lectura, y así lo anunció desde el título; además en el prólogo justificó la necesidad del texto, aduciendo la ausencia de obras de esta naturaleza, en contraste con el hecho de que sí estaban disponibles las vidas en romance de muchas santas ${ }^{34}$.

La obra tuvo una gran acogida entre el público. Es la vida de María más editada en toda la Península en la época que acotamos, tanto en catalán, como en castellano, e incluso contamos con obras derivadas de este texto, como veremos en el caso de Francisco de Trasmiera (1.8) y de Juan de Molina (3.2.2). En catalán se editó en cinco ocasiones antes de la aparición del Índice de Valdés ${ }^{35}$; y en castellano, en poco más de treinta años, se publicó al menos en seis ocasiones ${ }^{36}$. El texto fue vertido al castellano por un traductor anónimo pocos años después de su aparición en catalán; en el prólogo de la traducción se destaca el interés de la obra y la necesidad de su traducción. La versión castellana es muy fiel al texto original, en contenido y forma, y mantiene incluso el estilo artizado característico del autor valenciano ${ }^{37}$.

34 " [...] estimant ésser justa e rahonable cosa, que puix les vides de innumerables sanctes en vulgar prosa se troben scrites, que la gloriosa vida de aquesta alta reyna de paraýs, que és sancta sobre totes les sanctes, no deu ésser en la nostra valenciana lengua callada" (Peres, $1 \mathrm{v}$ ).

35 Se editó por primera vez en 1494 (Valencia, Nicolau Spindeler), solo un año después, en 1495 (Barcelona, Gelart Preus, Joan Luschner i Wendrell Rosenhajer), en 1506 (probablemente por Joan Joffré), 1516 (Valencia, Diego de Gumiel) y en 1551 (Barcelona, Carles Amorós), y todavía, pese a la prohibición inquisitorial, en 1742 (Barcelona, Pau Campins). Vid. Arronis (2012a: 58-77).

36 En 1516 (Sevilla, Jacobo Cromberger), 1517 (Sevilla, Jacobo Cromberger), 1525 (Sevilla, Juan Varela), 1526 (Toledo, Miguel de Eguía), 1531 (Sevilla, Juan Cromberger), 1549 (Toledo, Juan de Ayala). Vid. Arronis (2014:102)

37 Sobre la cuestión véase Arronis (2014: 103-110). 


\section{7}

Razón historial de las cosas de Nuestra Señora

Autor: Gómez García

Fecha de redacción: ca. 1512

Lengua: castellano

Edición: Sevilla, J. Cromberger, ca. 1512; ejemplar: Biblioteca Capitular y Colombina de Sevilla, 14-2-4(3). Vid. Segura y Vallejo (2003: 37)

Referencia de índices anteriores: Bengoechea $n^{\circ} 11$

Comentario: Con este curioso título de Razón historial de las cosas de Nuestra Señora, que vendría a valer tanto como 'discurso biográfico sobre María', se ofrece un texto de cinco páginas, que forma parte de un opúsculo misceláneo escrito por el clérigo toledano Gómez García, al que Gómez Redondo (2012: 1052) relaciona con el círculo de los Reyes Católicos y con su impulso a la reforma religiosa. Se trata del Oratorio devotíssimo impreso por Jacobo Cromberger en Sevilla hacia 1512. Del contenido de este pequeño libro en octavo de 32 hojas, ya se hizo eco Gallardo (1889: 1189-1191). Según Gómez Redondo (2012: 1065), el propósito de la miscelánea es servir a la iniciación en la vida contemplativa. Recordemos que en la página 5 del libro el autor cita como otra obra suya el Carro de dos vidas (activa y contemplativa), publicada en 1500 y considerada el primer tratado místico en lengua castellana ${ }^{38}$. Gómez Redondo describe el Oratorio devotíssimo en tres partes, orientadas al mismo fin contemplativo y unidas por las figuras de Cristo y de la Virgen: la primera parte en prosa instruye en la iniciación a la vida contemplativa y el necesario abandono del mundo; la segunda contiene versos dedicados a la Pasión de Cristo y a los gozos de María; la tercera, de nuevo en prosa, reúne oraciones dedicadas al sagrario y la Razón historial. Esta es una versión muy resumida de la vida de María, escrita con gracia ${ }^{39}$, que omite los episodios relativos a Jesús e incluso alguno propio de la Virgen, como la Inmaculada Concepción, quizá para huir de un dogma polémico, o la Visitación. Comienza por la Presentación en el templo y termina con la Asunción, atendiendo sobre todo a los episodios de tradición apócrifa. De acuerdo con Gómez Redondo (2012: 1069), esta vida de María es el remate perfecto para la tercera parte del libro, que responde a la orientación de la piedad femenina, constituida por plegarias en prosa,

que deben utilizarse en momentos concretos de la liturgia o en situaciones de especial

38 Vid. Pego (2004: 90) y la edición moderna de Carro de dos vidas. También escribió Lamedor espiritual y algunos versos devotos (1516), del que no se conoce ejemplar. Vid. Gómez Redondo (2012: 1053) y PhiloBiblon (BETA bioid 3904).

$39 \mathrm{Al}$ describir a María, por ejemplo: "Sin gestos. Sin boscezos e abrimientos de boca ante los hombres, ni con sonido estando sola. Sin furia. Sin osadía. Sin risa. Sin turbación. Fue acabada en todo saber y eloquencia. Fue llena de gracia. Tovo estado e altura de tres braços. Fue quasi de color de trigo, los ojos ruvios, e narizes iguales, cejas negras, complida de vulto e acatadura derecha. Manos complidas e dedos" (Gómez García, 86v-87r). 
devoción, ya ante el sagrario o el crucifijo, ya después de comulgar (...); son rezos para mujeres, con forma de soliloquio que permiten a la orante conformar un cauce interno de imitación de la vida de Cristo y de acercamiento a la Virgen María.

La Razón historial sería, pues, una lectura complementaria para otros momentos no litúrgicos.

La vida y excelencias de la sacratíssima virgen María nuestra Señora
Autor: Francisco de Trasmiera
Fecha de redacción: 1543
Lengua: castellano
Edición: Valladolid, Francisco Fernández de Córdova, 1546; ejemplar: Bibliote-
ca Nacional de España, USOZ 2896. Vid. Marsá (2007: 65-66), y Arronis (2012a,
121-125)
Referencia de índices anteriores: Bengoechea $\mathrm{n}^{\mathrm{o}}$ 6; Simón Díaz $\mathrm{n}^{\mathrm{o}} 18 \mathrm{y} \mathrm{n}^{\mathrm{o}} 19^{40}$

Comentario: No disponemos de más información sobre el autor que la del nombre, -que solo aparece en la licencia editorial, concedida en 1543, tres años antes de la edición-, y esta obra parece ser la única que se le atribuye ${ }^{41}$. Como ya demostramos en ocasión anterior (Arronis, 2012b), en realidad esta obra es una versificación de la ya citada Vida de la sacratíssima verge Maria de Miquel Peres (1.6), aunque en el texto no se hace ninguna declaración al respecto.

El autor ha adaptado la obra de Peres a partir de la traducción anónima castellana, (Arronis, 2014: 123-125) y ha realizado las modificaciones formales y estilísticas acordes a la nueva forma métrica. Para la narración del texto emplea las coplas de arte mayor, parece que siguiendo el modelo del popular Retablo de la vida de Christo fecho en metro de Juan de Padilla; y para las oraciones finales con que se cierra cada capítulo (siguiendo el esquema de Peres), las coplas reales o falsas décimas, composición métrica usual en la poesía castellana de la época, y empleada en las Coplas de Vita Christi de fray Íñigo de Mendoza. Estos parecen ser los modelos que inspiran a Trasmiera para llevar a cabo la versificación de la vida, y así lo indica en el prólogo introductorio ${ }^{42}$.

40 Simón Díaz (1985: 17) cita la misma obra en dos asientos: en el 18 aludiendo al nombre de Francisco de Trasmiera, aunque especificando "El nombre del autor consta solamente en el Privilegio"; y en el 19, donde cita la misma obra, con idéntico título e idéntinco colofón, como anónima. Parece claro que se trata de una duplicación errónea.

41 "Por quanto vos, Francisco de Trasmiera, me hezistes relación que vos avéys hecho cierta obra en metro, llamada La vida y excelencias de nuestra Señora, [...] et visto en el nuestro consejo, acatando que la dicha obra es útil y provechosa, y por os hazer merçed, túvelo por bien. E por la presente os doy licencia et facultad para que vos o la persona que tuviere vuestro poder podáys ymprimir y vender la dicha obra por tiempo de seys años [...]" (Trasmiera, $1 \mathrm{v}-2 \mathrm{r}$ ).

42 Leemos en el prólogo de Trasmiera: “[...] he buscado las hojas y flores de los verdes campos de la elegante poesía, y soy entrado en el más deleytoso vergel de la sagrada scriptura, donde he cogido de 
Trasmiera sigue fielmente la estructura y el hilo temático de la obra valenciana, e incluso reproduce idénticos los títulos de cada uno de los capítulos (Concepción y nacimiento de María, vida en el templo, matrimonio con José, Anunciación, Visitación, etc.). Solo suprime tres de los treinta episodios originales ${ }^{43}$, y elimina los milagros con que Peres cerraba cada capítulo, rasgo característico de la obra valenciana. Otra variación importante es la desaparición casi sistemática de las citas latinas presentes en el original, que o bien se suprimen o bien se parafrasean en castellano. También se abrevian los fragmentos exegéticos, de manera que el carácter teológico y doctrinal de la obra queda diluido, lo que favorece la lectura devocional. Los añadidos son escasos, y normalmente responden a necesidades formales del ejercicio de la versificación ${ }^{44}$.

La Vida de Trasmiera es, por tanto, otro exponente del género, pues narra de manera exhaustiva toda la vida de la Virgen, y supone además un ejemplo de la vigencia de los tópicos tardomedievales. Parece comprobarse que hasta la publicación del Índice, había cierta continuidad en la reelaboración de las obras marianas, que se iban adaptando a unas preferencias estilísticas concretas, imitando modelos vigentes más acordes con el público lector.

\section{Vidas de Jesús y María perdidas}

De los dos textos que reseñamos a continuación, del primero solo se conservan fragmentos de romanceamientos, y del segundo una mera referencia; podrían ser vidas de Cristo que incluían la vida de María.

diversos libros el fructo desta provechosa obra, la qual es yntitulada La vida de la sacratíssima virgen María. [...] estimando ser justa y razonable cosa que, pues la vida de Cristo escirpta [sic] en verso se halla, no fuera razón que la vida desta bendicta virgen, por ser madre suya, sin escrevir en verso quedase. $Y$ ansí ella, que es lumbre del claro sol de justicia, a alumbrado la escura noche de la ignorancia mía para en verso poder pintar en aqueste tan chico espacio alguna parte de sus gloriosos autos, [...]" (Trasmiera, $3 \mathrm{v}-4 \mathrm{r})$. Sorprende que ya desde el prólogo se aprecia la dependencia del texto de Peres: "E axí no he cerquat les fulles e flors dels verts camps de la elegant poesia, mas só entrat en lo delitós verger de la sagrada scriptura, on he collit de diversos libres lo fruyt de aquesta profitosa obra, la qual és intitulada La vida de la sacratíssima verge Maria. [...] estimant ésser justa e rahonable cosa que, puix les vides de innumerables sanctes en vulgar prosa se troben scrites, que la gloriosa vida de aquesta alta reyna de paraýs, que és sancta sobre totes les sanctes, no deu ésser en la nostra valenciana lengua callada. E axí ella, que és lum verdadera y mare del clar sol de justícia, ha illuminat la escura nit de la mia ignoràntia per a poder en aquest tan poch espay pintar alguna part dels seus gloriosos actes, [...]" (Peres, 1r-1v).

43 Elimina el capítulo metafórico “Com la gloriosa verge Maria és entesa per Marta y per Magdalena quant en lo seu castell acolliren a Jhesús, salvador nostre", en el que prácticamente no hay parte narrativa; el capítulo "Com la gloriosa verge Maria rebé lo preciós cors de son fill en la sancta cena y com combregava y confesava, y la oració que deya quant combregava", quizá porque lo juzgó poco ortodoxo, pues la presencia de María en el Cenáculo no era un motivo habitual en la tradición; y el capítulo "Com la gloriosa verge Maria confortava y aconsolava lo sant ladre y los altres dexebles aprés la mort del seu gloriós fill", quizá por razones similares.Vid. Arronis (2012b: 85-86).

44 La única excepción la constituye el último capítulo de la obra, relativo a la Asunción, pues se aleja parcialmente del original de Peres e incorpora fragmentos extensos que no proceden de la obra valenciana. 


\section{1}

\section{Vita Christi et Mariae}

Autor: Bernardo de Brihuega

Fecha de redacción: segunda mitad del siglo XIII

Lengua: latín y probablemente castellano; traducción anónima al portugués

Comentario: Bernardo de Brihuega fue canónigo de Sevilla, y recopiló por orden del rey Alfonso $\mathrm{X}$ vidas de apóstoles, mártires y confesores. Probablemente esa compilación se corresponda con la conocida como Genesi Alfonsii, que fue divulgada por toda la Península en tradición manuscrita e impresa ${ }^{45}$, y está relacionada con el proyecto de la General estoria, en la parte relativa a los Hechos de los Apóstoles y en general al Nuevo Testamento. Bautista comenta: "Dice Bernardo que nadie debe maravillarse si ha acabado escribiendo varios volúmenes sobre las vidas de los mártires y los santos, obra que ha emprendido por encargo del rey, pues este le hizo reunir muchos libros, y aun después de ello, le obligó a recorrer su reino en otras dos ocasiones en busca de varios textos más que faltaban en su obra" ${ }^{\prime 4}$.

Díaz y Díaz (1962) estudió los materiales de unas Vitae Patrum ${ }^{47}$, vidas latinas de apóstoles y mártires compiladas por Bernardo de Brihuega. De acuerdo con Fidalgo (2005: 306307), el cruce de datos permite establecer como muy probable que la magna obra del briocano constase de cinco libros, el primero "que fala do feito de Jesus Cristo e de santa Maria"48, el segundo de las vidas y pasiones de los apóstoles, el tercero de las vidas y pasiones de los mártires, el cuarto de las vidas y pasiones de confesores, y el quinto de las vidas y pasiones de vírgenes y otras santas.

Fidalgo (2005: 307-311) relaciona esa copia incompleta y desordenada, y el pasaje en que alude al contenido no conservado, con testimonios que evidencian romanceamientos de los textos de Brihuega, aunque carezcan de indicación de autor. Asimismo revela que los Miraglos de Santiago (ms. 10252 de la BNE) podrían ser traducción castellana de la parte correspondiente del canónigo hispalense ${ }^{49}$. Bautista (2014 y en prensa), apoyándose en un cotejo de los textos latinos, castellanos y portugueses, concluye que después de una primera compilación en latín el propio Brihuega pudo encargarse de una reelaboración en castellano, que habría tenido dos estadios. Del primero derivaría el material hagiográfico

45 Publicada en Valladolid en 1502; aunque no se conserva ningún ejemplar, sabemos que estaba "en español" (vid. Fidalgo, 2005: 308-309; y Bautista, 2014: 96).

46 "El rey y sus colaboradores", en Alfonso X El Sabio, véase enlace en la Bibliografía.

47 Conservadas en cuatro códices en la Biblioteca Universitaria de Salamanca (mss. 2538-2541).

48 Según la referencia portuguesa del Cód. Alc. 280, f. 40c.

49 Los edita Connolly (1990). 
del ms. 10252, no solo los Miraglos de Santiago, sino también, según Bautista, las demás Estorias de los santos y el fragmento de la vida de Cristo de ocho folios.

Más en relación con la vida de María estaría otro códice castellano que transmite casi la primera mitad del libro primero de Brihuega, según identificación de Bautista (en prensa): el ms. 11-144 de la Biblioteca Zabálburu, de la segunda mitad del siglo XIV o quizá del XV. Bautista describe el contenido de la parte que interesa aquí: "narración sobre los padres de la Virgen, sobre la infancia de esta, el nacimiento de Cristo, su infancia y milagros, y que se interrumpe con su predicación (queda trunco en la materia correspondiente a Mateo 23, Marcos 12,38 y Juan 20,45)", con ingredientes del Pseudo-Mateo en lo referido a los padres de la Virgen, a su vida, al nacimiento de Jesús y huida y vuelta de Egipto; del Evangelio de la Infancia de Tomás lo relativo a la vida y milagros de Cristo desde el regreso de Egipto hasta los doce años; y de los evangelios canónicos el resto.

En portugués se ha transmitido el libro segundo sobre los apóstoles y parte del libro tercero sobre los mártires ${ }^{50}$. Y por lo que respecta al tema que nos ocupa, también en portugués conocemos dos folios de la Vita Christi et Mariae, relacionados con el Evangelio de Nicodemo y con el Llanto de Magdalena ${ }^{51}$.

Adviértase que las referencias portuguesas dicen "feito", 'hecho', y no "vida", pero en todo caso alusivo a acontecimiento, peripecia, narración ${ }^{52}$. Se da la circunstancia de que el traductor castellano de los Miraglos de Santiago alude a "los fechos de Jhesu Christo", probablemente en referencia al fragmento de la vida de Cristo que contiene el mismo manuscrito (Fidalgo, 2005: 297 y 301).

Gracias al fragmento castellano conservado en la Biblioteca Zabálburu, se puede conjeturar que la Vita Christi et Mariae presentaría la biografía mariana como marco de la de Cristo, pero su final trunco impide saber si además de la materia bíblica y apócrifa, contendría otros elementos doctrinales o milagros. En todo caso, es un precedente muy notable por su atestiguada difusión en tres lenguas y obras diversas.

\section{2}

Vida de Jesús y María

Autor: Diego Sánchez de Valdés

Fecha de redacción: ca. 1484

Lengua: castellano

50 O segundo livro que fala de todo o feito e de todalas vidas e das paixões dos apostolos está en un códice alcobacense del siglo XV: Cód. Alc. 280. Y el Livro e legenda que fala de todolos feytos e payxões dos santos martires fue impreso en Lisboa en 1513. A propósito de esta edición, Deyermond (1990: 140) recoge la idea de que el propio Brihuega podría haber realizado una versión castellana intermedia entre su obra latina y la portuguesa.

51 Vid. PhiloBiblon, texid BITAGAP 5937.

52 Bernardo de Brihuega se refiere a los relatos como "vitae" o "passiones", según corresponda, pero en la rúbrica del libro IV anuncia "gesta et miracula confessorum" (Díaz, 1962: 158). 
Comentario: Solo conocemos esta obra por una referencia documental, contenida precisamente en otra vida que reseñamos más abajo (3.1.2): la Vida y excelencias y miraglos de santa Anna y de la gloriosa nuestra señora santa María fasta la edad de quatorze años (Sevilla, J. Cromberger, 1511). Es en este texto, atribuido a Juan de Robles, canónigo de San Isidoro de León, donde leemos una afirmación del autor en la que declara el interés que suscitaría la edición de una vida de María en romance, escrita por:

un famoso doctor deste reyno llamado don Diego Sanches de Valdés, abad de San Guillermo, en la Iglesia de León, el qual compuso un devoto libro en romance muy fundado y copioso de la vida de Nuestra Señora y de Nuestro Redemptor; y parece que por culpa o negligencia de algunas personas a cuyo poder vino el dicho libro original, no ha sido magnifestado, ni dado a imprimir, y ciertamente sería un libro muy provechoso si se imprimiesse $^{53}$.

Según Gómez Redondo (2012: 987) cabe dar esta obra aludida por perdida. No obstante, la breve referencia resulta interesante por diferentes motivos. Por un lado, pese a que parece ser una vida de María y de Jesús, es decir, que no se centra de manera exclusiva en la de la Virgen, la alusión a su carácter "fundado y copioso" nos permite imaginar una obra donde la temática mariana se trataba con exhaustividad, de ahí, precisamente, la reivindicación de Robles. Por otro lado, el comentario sugiere el interés y el anhelo latente por lecturas de esta temática en romance, y encierra cierta queja velada por no disponer de más textos de estas características.

No podemos ofrecer una datación exacta para el texto. De Diego Sánchez de Valdés la única noticia histórica que hemos hallado lo sitúa el 3 de octubre de 1484 como abad de la iglesia de San Guillermo de León ${ }^{54}$, fecha que nos ayuda, por tanto, a establecer la datación aproximada del texto. La coincidencia geográfica de ambos autores, el desconocido Diego Sánchez de Valdés y Juan de Robles, canónigo de San Isidoro, parecen reflejar la existencia de un foco de devoción mariana en la diócesis de León (vid. Gómez Redondo, 2012: 987).

\section{Textos afines a las vidas de María}

\subsection{Vidas de María parciales}

Van a continuación los relatos que tratan solo algunos episodios biográficos de María, de manera que no pueden considerarse vidas canónicas.

53 Citamos a partir de la reedición de Robles en 1550, en Sevilla por Domenico de Robertis, ff. b7v-b8r. 54 Se trata de un protocolo notarial del Catálogo del Archivo Histórico Diocesano de León. Recogido por Gregorio Boixío en 2003 (http:/ / www.vegasdelcondado.com/referencias.htm). 


\subsection{1}

Vida de María

\section{Anónima}

Fecha de redacción: siglo XV

Lengua: castellano

Manuscrito: forma parte de un códice misceláneo devocional, ms. 8744 de la Biblioteca Nacional de España, ff. 395v-400r. Vid. Gómez Redondo (2007: 3855-3859)

Comentario: Es un opúsculo de cuatro folios y medio, centrados en la infancia de María, en su vida en el templo. Gómez Redondo (2007: 3855) afirma que la autoría se atribuye a san Jerónimo, pero en realidad el texto cita distintas autoridades. La primera mitad la refiere a san Jerónimo: presenta a la Virgen como modelo femenino de ocupación, de ordenación del tiempo entre devociones y trabajo manual, y de huida del ocio, y la muestra luego en su familiar trato con un ángel. Son elementos que se remontan al evangelio apócrifo atribuido a san Jerónimo (el Pseudo-Mateo) ${ }^{55}$. La segunda mitad se compone con citas de sermones de Genardio, Senero y Egidio, que alaban las virtudes de la Virgen como santa niña en el templo.

Vida y excelencias y miraglos de santa Anna y de la gloriosa nuestra señora
santa María fasta la edad de quatorze años
Autor: Juan de Robles
Fecha de redacción: 1511
Lengua: castellano
Edición: Sevilla, J. Cromberger, $1511^{56}$; ejemplar: Biblioteca Nacional de
España, R-31388
Referencia de índices anteriores: Bengoechea $\mathrm{n}^{\mathrm{o}} 5 \mathrm{y} \mathrm{n}^{\mathrm{o}} 21$

Comentario: Ya hemos citado líneas arriba a Juan de Robles, bachiller, canónigo regular de San Isidoro de León, como autor de la referencia a Diego Sánchez de Valdés (2.2). En la dedicatoria a la reina doña Juana y en el epígrafe siguiente se dice:

deven ser reprehendidos los que escrivieron las vidas de los sanctos y destos dos tan excelentes [los padres de la Virgen] no se acordaron. Cuyo defecto suplió el bachiller Juan de Robles, canónigo reglar del monesterio de Sant Isidro de León, muy devoto de señora santa Anna. El qual de muchas partes copiló lo que le pareció que hazía para honra y alabança desta bienaventurada sancta, y por que esto fuesse a todos comunicado quiso se impri-

55 Una versión abreviada del Pseudo-Mateo es el Liber de infantia Salvatoris, conocido asimismo como Liber de Nativitate sanctae Mariae, que también se atribuye a san Jerónimo. El contenido de ambos apócrifos fue difundido en el capítulo de la Natividad de la Virgen de la Legenda aurea. Véase también 3.3.3.

56 Se reeditó en 1522, 1523, 1550, 1567 y 1590. 
miesse. (...) La qual fue trasladada de latín en romançe (...) por un canónigo reglar (...) de la orden de Sant Augustín (...). A lo qual dio alguna ocasión el descuido o negligencia de los que trasladaron de latín en romance el flos sanctorum y las otras istorias de los sanctos y dexaron a sancta Anna olvidada seyendo tan principal y tan gloriosa sancta.

Esta obra trata más de la madre de la Virgen que de ella misma, pero plantea sobre todo el paralelismo de las virtudes de ambas, para lo que se recurre a un sólido aparato teológico, de modo que la obra contiene mucha doctrina, además de las dos vidas y milagros de santa Ana. Así lo advierte Gómez Redondo (2012: 988), que describe cómo el relato dedicado a los padres de María se interrumpe para ocuparse en seis de los doce capítulos de la infancia y educación de la Virgen, con alabanza de las excelencias de su alma y de su cuerpo. Los tres últimos capítulos consisten en una defensa del culto a santa Ana y el relato de sus milagros.

\subsection{Vidas de María con estructura atípica}

Hay otros libros que no son estrictamente relatos de la biografía de María, pero se ocupan con profusión de los episodios y misterios de su vida terrenal:

\section{2 .1}

Libro de las historias de Nuestra Señora

Autor: Juan López de Salamanca

Fecha de redacción: 1465-1468

Lengua: castellano

Manuscrito: 103 de la BNE. Para su descripción, veáse Jiménez Moreno (2009: 13-18)

Referencia de índices anteriores: Rodríguez p. 187

Comentario: Juan López de Salamanca fue un teólogo dominico, autor de diversos textos religiosos ${ }^{57}$, defensor del "dogmatismo más ortodoxo", en palabras de Gómez Redondo (2007: 3860). De la obra mariana que nos ocupa se conserva el primer libro, que trata de las festividades de la Inmaculada Concepción, Natividad de María, la Encarnación y Visitación. El segundo libro, que no se ha conservado, trataría el Nacimiento de Jesús, la Presentación en el templo, la Asunción y el milagro de las nieves de agosto. Ahora bien, como advierte Jiménez Moreno (2009: 27), no es un mero devocionario de las fiestas marianas, porque contiene mucha doctrina y porque además presenta la singularidad de estar escrito como un diálogo entre la Virgen y la dedica-

57 Fruto de una controversia teológica escribió un Tratado de la penitencia según la Iglesia Romana; también han llegado hasta nosotros sus Evangelios moralizados; y redactó otras obras de las que solo tenemos referencias, como la Vida de san Vicente Ferrer, y puede que otras hagiografías sobre el fundador y primeros dominicos. 
taria, la joven doña Leonor de Pimentel, Condesa de Plasencia, de la que Juan López era director espiritual. Es más bien un manual de meditación religiosa, como estima Gómez Redondo (2007: 3859), que lo describe en detalle; un libro austero, pero no exento de alardes literarios, como la viveza del diálogo, la descripción de la belleza de la Virgen, o el uso de la prosa rítmica. Como dice Jiménez Moreno (2009: 455), a pesar de la declaración del autor sobre que su estilo es humilde, sí hay recursos formales, aunque supeditados a la eficacia práctica. A medida que avanza, el diálogo muestra el perfeccionamiento intelectual y espiritual de la condesa, convertida en alumna de la Virgen.

Estas características alejan la obra de la consideración de una vida de María, pues no es un relato lineal de su biografía, de modo que parece plausible la interpretación que ofrece Jiménez Moreno (2009: 23-28) sobre el título del libro, a partir de las palabras del autor: "Propuse exarar por estensso un libro, más provechoso que graçioso, en el qual acomulase e juntasse las devotíssimas e santíssimas historias que conprehenden toda la vida de nuestra Señora". Interpreta que historias no debe entenderse en sentido narrativo, como el relato de la vida de María, sino iconográfico, aunque en este caso las estampas que ilustran las festividades marianas sean verbales.

La copia transcribe otro texto anterior, lo que significa que la obra tuvo cierta difusión, probablemente entre las damas del círculo de la condesa. Otro libro del mismo autor, los Evangelios moralizados, acabó en la imprenta después de haber tenido difusión manuscrita en ámbitos nobiliarios y eclesiásticos (Jiménez Moreno, 2009: 16-17). Un indicio de que para el texto mariano Juan López pensaba en la lectura devota de mujeres y no, por ejemplo, en la de clérigos, es que cita antífonas, himnos y otros pasajes del breviario de memoria, siempre en romance y no siempre con exactitud, a diferencia de las precisas citas latinas que inserta en los Evangelios moralizados, porque van dirigidos a religiosos (Jiménez Moreno, 2009: 26-27).

\section{2 .2}

Vergel de Nuestra Señora

Autor: Juan de Molina

Fecha de redacción: 1542

Lengua: castellano

Edición: Sevilla, Domenico de Robertis, 1542; ejemplar: Biblioteca Valenciana de Sant Miquel dels Reis, XVI/72. Véase descripción en Arronis (2012a, 107108)

Referencia de índices anteriores: Bengoechea $\mathrm{n}^{\mathrm{o}} 15^{58}$

58 Bengoechea cita la obra de Molina con el título De la vida y excelencias de Nuestra Señora, pues la identifica con la traducción castellana anónima de la de Miquel Peres. 
Comentario: Esta obra ha sido siempre citada como una traducción al castellano de la Vida de la sacratíssima verge Maria de Miquel Peres (1.6), porque así lo declara el autor en la epístola proemial que precede al texto ${ }^{59}$. Sin embargo, como ya demostramos en un estudio anterior (Arronis, 2013), pese a tal afirmación, el Vergel es una composición nueva articulada por Molina, donde reelabora y refunde distintas fuentes, entre ellas la obra valenciana de Peres, para conseguir un nuevo propósito devocional.

El Vergel, como su título indica, es una obra alegórica que presenta la figura de la Virgen como un jardín fortificado (cap. I-II), y trata distintos aspectos de la doctrina mariana a través de la descripción de sus elementos (torres, puertas, palacios, cipreses...). Aborda así las virtudes teologales y cardinales (cap. III-X) presentes en la Virgen, los gozos (cap. XII-XVIII), los dolores (cap. XIX-XXVI), los privilegios (cap. IV-IX), las consolaciones de María (cap. XI-XIV), etc. En cada núcleo temático trata unos atributos y unos misterios marianos, e incorpora tanto episodios de la vida de María que los ejemplifican, como argumentaciones teológicas y exegéticas sobre cada cuestión. La naturaleza biográfica pretendida por Peres, así como su secuenciación cronológica, quedan por completo desdibujadas, y los episodios vitales solo importan en tanto que ejemplifican la doctrina mariológica. En el tratado de Molina, además, se han suprimido los relatos de los milagros, y las oraciones con que Peres concluye cada capítulo. Los cambios en la obra obedecen a una función devocional distinta: la narración detallada de la vida de la Virgen, que en Peres se ofrecía como modelo, aquí queda supeditada a la alabanza del carácter excepcional de la santidad y de las virtudes de María, mostradas a través de la alegoría del vergel.

\subsection{Vitae Christi que incluyen la vida de María}

Por último, nos ocupamos de un conjunto de obras que, si bien contienen el discurso completo de la vida terrenal de la Virgen ordenado de manera cronológica, no podemos clasificar como vidas de María, pues su objetivo y finalidad no es únicamente este. Se trata de algunas vitae Christi surgidas en el contexto peninsular, especialmente en el último decenio del siglo $\mathrm{XV}$, como consecuencia e instrumento al tiempo de las nuevas vías de espiritualidad. La vida de María y la de Jesús aparecen como un continuum indivisible, de manera que representan y sintetizan la salvación. Los episodios de procedencia apócrifa y canónica más representativos de las vidas de Jesús y María, frecuentemente enriquecidos con extractos de tratados teológicos, permiten orientar

59 “[...] Reciban pues vuestras reverencias, reverenda Madre priora y colegio muy sancto, y con vosotros todos los devotos de la reyna de los ángeles, su vergel, a mi ver, bien plantado y no mal ordenado, y en esta lengua, por vuestro respecto, con mi trabajo nuevamente nacido; el qual, compuesto primero por Miguel Pérez, ciudadano de Valencia que en gloria sea, hombre de gentil ingenio y muy virtuosa vida, hasta aquí no era tan leydo por estar en la lengua que estava" (Molina, 3r). 
la lectura a la contemplación y a la comprensión de los pasajes, lo que favorece una devoción tan emotiva como intelectual.

Dado que la mayoría de estas Vitae Christi son traducciones, en aras de una exposición más clara, excepcionalmente en este apartado cada traducción recibe una entrada aparte, y no solo las obras originales.

\subsection{1}

Vita Christi

Autor: Francesc Eiximenis

Fecha de redacción: ca. 1404

Lengua: catalán

Manuscrito: 209 de la Biblioteca Històrica de la Universitat de València

Comentario: La Vita Christi de Francesc Eiximenis es, junto a la Vita Christi del Cartujano, una de las vidas de Cristo más difundidas en la Península en la baja Edad Media, especialmente en los territorios catalanoparlantes de la Corona de Aragón ${ }^{60}$. Eiximenis quiso compilar una exhaustiva vita Christi para los fieles devotos, y por eso la redactó en catalán, y no en latín, como otras obras suyas; intenta ser una summa cristológica dirigida al público laico (Hauf, 1978: 85). El marcado carácter enciclopédico del tratado se observa también en la combinación de materiales de distinta procedencia; se funden en ella tanto reflexiones patrísticas sobre la exégesis bíblica o glosas, con elementos legendarios de carácter popular, descripciones emotivas, disertaciones morales o didácticas, oraciones contemplativas, milagros, etc. Eiximenis recopila toda la información de que dispone sobre cualquier episodio relacionado con las vidas de Jesús o de su madre, a la que dedica mucha atención ${ }^{61}$. La espiritualidad franciscana del autor se aprecia especialmente en la emotividad de algunos de sus pasajes, y en la alusión frecuente a autores contemplativos, como Ubertino de Casale o Ángela de Foligno. El tratado se articula en 10 libros y un total de casi setecientos capítulos. Los

60 Aunque no solo, ya que Hernando de Talavera la tradujo al castellano (3.3.2). Además, ya anteriormente fragmentos de esta Vita Christi se habían incorporado a los testimonios de la compilación A del Flos sanctorum castellano, en los capítulos dedicados a las festividades cristológicas (Baños, 2009: 166).

61 Vemos un ejemplo del detalle con que describe a María, dando cabida a motivos populares difundidos por la devoción contemplativa: "totstemps la gloriosa, mentres que estech en lo temple de Déu, xica infanta de tres anys fins al jorn que morí, totstemps portà cilici a la carn, e havia poques vestidures e solament aquelles que eren necessàries a ella, ab les quals soferí molt fret e molta calor. Diu que eren de burell, feyt de aytal lana com se leva de les ovelles sens neguna tintura, axí com ja dessús dit. Diu encara que jamés no portà calces, mas portava los peus cuberts damunt per honestat; null temps hac lit ne jach en lit depuýs que fon posada en lo temple de Déu, ans dien que deya que lo lit era gran enemich de puritat, e en açò singularment l'an volguda ressemblar alguns grans sos devots e amichs spirituals de puritat. [...]E diu sent Jeronni que ella en ses formes era dona fort bella, emperò axí pura que l'esguart de la sua santa cara engendrava castedat e puritat en aquells qui la veyen; e aquesta, ço diu, és la rahó que jamés no fon per negún cobejada, segons que han los antichs jueus en les lurs antigues històries, com ja damunt és dit." (Eiximenis, ff. 45r-45v). 
libros tercero y cuarto dedican una mayor atención a la narración de la infancia de María y a su simbología, y en el décimo se tratan los últimos años de su vida y la Dormición y Asunción ${ }^{62}$. Aunque grosso modo la estructura de la obra sigue un orden cronológico, las continuas disertaciones del autor alteran el tiempo de la narración, que en ocasiones salta de un episodio a otro para volver después sobre sucesos anteriores. 3.3 .2

\section{Vita Christi}

Traductor: Hernando de Talavera

Fecha de traducción: 1496

Lengua: castellano

Edición: Granada, J. Pegnitzer y M. Ungut, 1496; ejemplar: Real Biblioteca, $\mathrm{I} / 7$

Comentario: El jerónimo Hernando de Talavera, arzobispo de Granada y confesor de Isabel la Católica, proyectó la traducción de la Vita Christi de Francesc Eiximenis al castellano, considerando la exhaustividad de fuentes que contenía y su marcado carácter contemplativo que favorecía el ejercicio espiritual. También se ocupa, por tanto, de la vida de la Virgen, como parte inseparable del mismo proceso de contemplación. Sin embargo, la traducción de la obra quedó incompleta, y solo se publicó el primer volumen en Granada en 1496. Su propósito era el mismo que el del fraile catalán, el de facilitar el mejor tratado de contemplación cristológico para seglares, por lo que tradujo, enmendó y sintetizó la magna obra de Eiximenis ${ }^{63}$. Sin embargo, la tarea quedó interrumpida, pues finalmente el mismo Talavera promovió la traducción de la Vita Christi del Cartujano, encomendada ahora a fray Ambrosio de Montesino (vid. 3.3.6).

\section{3 .3}

Libro que se dice Infancia Salvatoris

Autor: Pseudo-Bernardo

Fecha de redacción: ca. 1493

Lengua: castellano

Edición: Burgos, Juan de Burgos, ca. 1493; ejemplares: Biblio-

teca Nacional de España, INC/1424; Arhiginnasio de Bolonia, 16.K.II.20

Referencia de índices anteriores: Bengoechea $n^{\circ} 1$

Comentario: Atribuido a un dudoso "sant Bernardo, abbad de Caravaca". Como recoge PhiloBiblon (BETA bioid 1396), "Caravaca" podría ser corrupción de "Clara-

62 Vid. una descripción del índice más detallada en Arronis (2012a: 234-235).

63 Sobre la intervención de Hernando de Talavera en la traducción de la Vita Christi, vid. Hauf (2001). 
val", así que probablemente la atribución apunte al "doctor melifluo", en un caso de confusión también con el "doctor seráfico", si se atiende a que el Libro parece ser un romanceamiento castellano de las Meditationes vitae Christi atribuidas a san Buenaventura. Escritas a inicios del siglo XIV, las Meditationes constituyeron una de las obras más influyentes y representativas de la nueva espiritualidad emotiva de los siglos XIV y XV. El enfoque meditativo que las distingue hace que prime el tono fervoroso y emotivo de la narración sobre las disertaciones teológicas, en esta ocasión casi inexistentes, y así se mantiene en la versión castellana, donde a cada fragmento de narración sigue una exclamación devota que exhorta al lector a la reflexión y la contemplación ${ }^{64}$. La obra se caracteriza, como la original que reelabora, por la plasticidad con que recrea las escenas persiguiendo la intensidad emotiva, y por el celo doctrinal, pues apreciamos cierto afán por depurar los episodios de procedencia popular, algunos de ellos muy extendidos en la tradición mariológica ${ }^{65}$. Esta predilección por el tono narrativo y la búsqueda de la brevedad y la concisión favorecen que el Libro sea leído como una historia, lo que sería difícil, por ejemplo, con la magna obra de Eiximenis, interrumpida constantemente por largas disertaciones teológicas y doctrinales. El Libro se compone de treinta y dos capítulos, y cada uno de ellos se centra en un episodio de la vida de María o de Jesús, ordenados desde la Concepción e infancia de la Virgen hasta su Dormición y Asunción. Los capítulos dedicados a María son, por tanto, como en la mayoría de las vitae Christi, los iniciales (cap. I-XIII) y los finales (XXXII), pues enmarcan la vida de Jesús. Gómez Redondo (2012: 891) señala que la parte sobre Jesús sigue esencialmente los evangelios canónicos, mientras que los capítulos sobre María beben de los apócrifos, y en concreto invocan el relato atribuido a san Jerónimo, como el opúsculo visto arriba (3.1.1). En el Libro leemos: “Mas sant Gerónimo escrivió la vida desta santíssima Virgen. E dize..." (f. 3v). El capítulo anterior a esta referencia, que es el primero, coincide en síntesis con la secuencia correspondiente del apócrifo que lleva el mismo título, Liber de infantia Salvatoris, también atribuido a san Jerónimo, como el Pseudo-Mateo, del que es versión abreviada.

Por otro lado, debe destacarse que el incunable incorpora además un conjunto de milagros marianos (ff. 56r-63r) que ninguna relación guarda con las Meditationes latinas, y una Visión de san Pablo de las penas del Infierno (63v-64v). Por la temática, nos interesa especialmente el conjunto de milagros, que, tal y como se declara, han sido

64 "O, alma devota, contempla cómo la Virgen doncella está inclinada, abaxados los ojos en tierra, porque se hallaba inprovisa destas palabras. Ca non se reputava nin se veýa desta cosa digna. Ca oyendo decir de sí tan grandes cosas, las quales nunca fueran dichas de ninguna persona, estaba fuera de sí" (Liber, a6r).

65 Pensamos, por ejemplo, en el episodio de las dos parteras que asisten a la Virgen, muy difundido en la tradición popular e incluido en la Legenda aurea y en sus versiones en romance, pero ya depurado en las Meditationes. 
extraídos de las festividades marianas compiladas en el flos sanctorum: "Porque los miraglos suelen comover a los omes a devoción, son escriptos en un libro que es dicho Flos Sanctorum, e las fiestas de sancta María, e cuéntanse así" (fol. 56r). De los once milagros de la colección, todos menos los dos referidos a san Ildefonso están en efecto en la Legenda aurea, fuente de los flores sanctorum ${ }^{66}$. Pero los del santo toledano no derivan de Vorágine, así que los milagros podrían proceder de un flos sanctorum castellano que los contuviera $^{67}$, o podrían ser una interpolación de material de distinto origen, pues en realidad vienen a constituir una breve Vida de san Ildefonso. Precisamente sabemos que Juan de Burgos editó al menos un santoral castellano y era dado a las interpolaciones (vid. Baños, 2012: 88-89). En opinión de Gómez Redondo (2012: 1248), la inclusión de estos dos milagros de carácter más doctrinal, sugeriría el propósito de instruir a los clérigos, pero no condice con ello el descuido de las rúbricas de ambos milagros ${ }^{68}$, ni el carácter ligero del Libro, que apuntan más bien a una lectura devota no profesional.

Precede a los milagros una especie de brevísima vida de María, consistente en el cálculo de los años que vivió la Virgen, similar a los del comienzo del capítulo de la Asunción de la Legenda aurea ${ }^{69}$. Esta alusión biográfica con que se introducen los milagros nos hace recordar el consolidado modelo de vida y milagros seguido por muchos hagiógrafos e impuesto también en las expectativas de muchos lectores. Ese mismo esquema podría haber inspirado esta colección de milagros como cierre del Libro en general, sin contar con el último folio y medio de la Visión de san Pablo (vid. Gómez Redondo 2012: 891).

(3.3.4, 3.3.5 y 3.3.6) La Vita Christi del Cartujano Ludolfo de Sajonia, escrita a mediados del siglo XIV, fue otro de los textos claves de la nueva espiritualidad centrada en la contemplación. El texto del Cartujano seguía, como en los casos anteriores, el hilo cronológico de la vida de María y de Jesucristo, ocupándose de los episodios principales contenidos en los evangelios canónicos y apócrifos. Pero el gran logro del de Sajonia fue el de promediar el tono contemplativo presente en la Meditationes vitae Christi con

66 En capítulos marianos: en la Natividad de María los primeros cinco milagros; en la Anunciación el del bandolero; en la Asunción el del juicio y el del niño judío. Y en cambio en la vida de Santiago el Mayor el del romero engañado. Fradejas Lebrero edita la Visión de san Pablo (1993a) y los once milagros (1993b), que solo están completos en el ejemplar boloñés, porque al de Madrid le falta el folio LXII.

67 El ms. 12688 de la Biblioteca Nacional y el h-III-22 de la de El Escorial contienen la vida de san Ildefonso, pero la versión que transmiten de ambos milagros no es idéntica a la del texto que nos ocupa.

68 El primer milagro sobre san Ildefonso lleva el siguiente título: “Miraglo quando nuestra señora santa María fue a visitar a sant Ylifonso", cuando en realidad se trata del milagro de santa Leocadia y la Virgen no aparece; en consecuencia, la segunda rúbrica también es errónea: "Miraglo de cómo aparesció Nuestra Señora la segunda vez a sant Ylifonso".

69 En nuestro libro comienza: “La Virgen avía catorze años quando el obispo la embió del templo así como es dicho de suso, e dende a tres meses saludola el ángel". Y termina: "Así que la vida que hizo en este mundo la preciosa virgen sancta María fueron sesenta años, e aún no fueron conplidos ca menguan veynte e quatro días que ay desde el día que la Virgen santa María fue subida a los cielos fasta el octavo día de setiembre en que nasció sancta María, e así dexada esta materia començarán los miraglos". (f. 56r) 
la síntesis exhaustiva de autoridades patrísticas que glosaban los acontecimientos narrados. La Vita Christi del Cartujano es una obra ambiciosa, concebida con voluntad enciclopédica: fusiona y resume las opiniones de más de sesenta autores cristianos, junto a disertaciones morales y dogmáticas, meditaciones guiadas, etc. y concluye cada episodio con una oración. Es una obra piadosa que quiere conmover el espíritu de los fieles a través de la lectura, pero también, y sobre todo, una síntesis de fuentes patrísticas que contribuye al conocimiento de la doctrina cristiana. En el Concilio de Basilea (1431-1449) se señaló la idoneidad de su carácter divulgativo, por lo que en los decenios siguientes, especialmente a finales del siglo XV, se sucedieron las traducciones a las lenguas romances.

3.3.4

Vita Christi

Traductores: monjes cistercienses de Alcobaça, Bernardo de Alcobaça y Nicolau Vieira.

Fecha de traducción: 1445

Lengua: portugués

Manuscritos y edición: mss. Alc. 451-453 de la Biblioteca Nacional de Portugal. Impresa en Lisboa, Valentim Fernandes y Nicolau de Saxónia, 1495; ejemplar: Biblioteca Nacional de Portugal, INC 553-554 e INC $566-567^{70}$

Comentario: es la primera traducción de la Vita Christi del Cartujano en la Península. Fue publicada en cuatro partes en Lisboa, por impresores alemanes (Valentim Fernandes y Nicolau de Saxónia), en 1495, por orden de la reina Leonor, esposa de João II. Branco da Silva (2009) prepara una edición basada en el incunable, que está más cerca de la lengua original y presenta algunas intervenciones interesantes, según el cotejo con el manuscrito y con la fuente latina. El texto del incunable no transcribe el manuscrito, sino que ambos parecen remontarse a un arquetipo común.

70 Más información sobre los ejemplares manuscritos e impresos de la traducción portuguesa puede consultarse en PhiloBiblon (BITAGAP texid 1004-1007). Entre las primeras versiones en romance de la Vita Christi del Cartujano, Gómez Redondo (2012: 976) menciona las portuguesas y data la francesa en 1467. 


3.3.5
Vita Christi
Traductor: Joan Roís de Corella
Fecha de traducción: finales del siglo XV
Lengua: catalán
Edición: la obra, por su gran extensión, se publicó en cuatro volú-
menes separados: en 1495 se imprimieron Lo Quart del Cartoixà y Lo
Terç; Lo Primer del Cartoixà en 1496, y Lo Segon del Cartoixà en 1500
(Riquer, 1964: 270) ${ }^{71}$. Ejemplares: Lo Primer, Biblioteca de Catalunya,
10-VI-14 (a); Lo Segon, Biblioteca de Palacio, I/ 88; Lo Terç, Bibliote-
ca de Catalunya,10-VI-13; Lo Quart, Biblioteca Nacional de España,
INC/2737(2)

Comentario: Después de las portuguesas, la siguiente traducción peninsular es la catalana del valenciano Joan Roís de Corella. Mossén Corella, "mestre en sacra teología", y figura destacada de los círculos literarios de la burguesía valenciana de finales del XV (como se ha visto en 1.2), llevó a cabo la magna traducción de Lo Cartoixà en las últimas décadas del XV, versión que destaca por la artificiosa prosa característica y por el estilo patético que imprime su autor ${ }^{72}$, que modifica notablemente el texto original (Furió, 2013).

\subsection{6}

\section{Vita Christi Cartuxano}

Traductor: fray Ambrosio de Montesino

Fecha de traducción: finales del siglo XV

Lengua: castellano

Edición: los cuatro volúmenes de la traducción de Montesino se imprimieron separadamente en Alcalá de Henares por Estanislao Polono entre 1502 (1r y 4) y 1503 ( $3^{\circ}$ y $2^{\circ}$ ). Ejemplares: Biblioteca Nacional de España, U/1399 (para otros ejemplares, vid. Philobiblon (BETA texid 4086)

71 Lo Quart del Cartoixà se imprimió por primera vez en febrero de 1495 y, tras su gran acogida, se reeditó solo unos meses después. Los volúmenes que habían gozado de mayor éxito, Lo Quart y Lo Primer, se volvieron a imprimir en 1513 y 1518, respectivamente. Gómez Redondo (2012: 976) cita la edición de 1513 de Lo Quart como la única edición de la traducción corellana; no da noticia de las ediciones incunables de todos los volúmenes.

72 Lo vemos en este ejemplo: “ $\mathrm{O}$, adolorada senyora nostra, Verge, mare trista, ab quina dolor ton fill unigènit en tanta pressa seguies! Quit sostenia? Qui t'ajudava? $O$, quina tragedia de dolor presentes a tots aquels qui a tu e ton fill amen! Les entramenes nos squinces, e de làgremes los pits nos abeures; $a b$ tu anam, mare dolorosa, a tu acompanyam, a tu seguim, hi ab tu e per tu ensemps ab ton fill volem que nostra vida muyra". (Lo Quart, f. 30r) 
Comentario: Parece ser que Fray Ambrosio de Montesino llevó a cabo la traducción castellana de la Vita Christi Cartuxano por encargo de la reina Isabel y su confesor fray Hernando de Talavera. Según Gómez Redondo (2012: 974), la mayor idoneidad de esta vida de Cristo favoreció su promoción editorial desde los círculos de la reina, por lo que quedó incompleta la edición de la Vita Christi de Eiximenis que fray Hernando de Talavera había iniciado unos años antes. Aunque fiel al texto latino, la traducción de Montesino no es literal: respeta los fragmentos referidos a la historia evangélica de las vidas de María y Jesús, pero se aleja en muchos de los comentarios y disertaciones.

\subsection{7}

\section{Vita Christi}

Autora: Isabel de Villena

Fecha de redacción: ca. 1463

Lengua: catalán

Edición: Valencia, Lope de Roca, 149773; ejemplar: Biblioteca Nacional de España, INC/1973

Referencia de índices anteriores: Bengoechea no 4, Rodríguez p. 187

Comentario: Un caso especial lo constituye sin duda la Vita Christi de Isabel de Villena. La redacción de la obra debió de iniciarse a partir de 1463, cuando Isabel de Villena ocupó el cargo de Abadesa (Hauf, 1995: 26-33), pero se publicó póstumamente. El público femenino para el que sor Isabel escribe la obra, las monjas clarisas del convento de la Trinidad, condicionó esta vita Christi, en la que los personajes femeninos, especialmente María y Magdalena, adquieren una gran presencia ${ }^{74}$. Otras particularidades que singularizan la obra son la detallismo de la narración ${ }^{75}$, la inclusión de elementos alegóricos (que simbolizan, por ejemplo las virtudes presentes en la Virgen) ${ }^{76}$, o la

73 Se reeditó pocos años después, en 1513 en Valencia por Jorge Costilla y de nuevo en 1527, en Barcelona por Carles Amorós.

74 Muchos autores, debido al protagonismo que María desempeña en esta obra, consideran que sería más adecuado hablar de una Vida de Cristo y María, que de una vita Christi propiamente. Así lo hace el propio Bengoechea $\left(1984, n^{\circ} 4\right)$, que no duda en incluir este título entre las vidas de la Virgen publicadas en el siglo XV.

75 Vemos el detalle con que se narra la preparación de María para sus esponsales, fragmento imaginado por la abadesa para embellecer el relato: "E la reverend matrona Anna féu vestir a la senyora les millors robes que tenia. Ab tot fossen pobrelletes, eren honestíssimes e molt netes. E estés-lis los cabells sobre les espatles, que li donaven tanta bellea ornament quia nunquam fuit tam bene coopertus Salamon in omni gloria sua, car nunca fon tan ben abillat Salamó en tota la glòria sua com aquesta senyora ab la sua natural bellea e composició virtuosa" (Escartí, 2011: 79).

76 Así por ejemplo, entre los capítulos 24 y 36 vemos cómo las virtudes marianas, representadas como doncellas, acompañan a María en el momento de la Anunciación para guiar a la Virgen en su respuesta: "la noble e gentil donzella Esperança", "l'excel lent e ínclita donzella Fe", "la noble e invincible Paciència", "la insigne Fortalea", "la gentil donzella Prudència”, etc. Vid. Escartí (2011). 
adición de episodios que no proceden de los evangelios apócrifos ni canónicos. Para Isabel de Villena la invención es un recurso lícito para conseguir la devoción emotiva, e imagina numerosas anécdotas protagonizadas por la Virgen, como distintos encuentros entre esta y santa Ana (caps. LXXXI, LXXXIII, LXXXIV, XCV)77, o la descripción de escenas cotidianas de la Sagrada Familia (caps. LXXXVIII-XCV) ${ }^{78}$. Incorpora, asimismo, episodios extendidos en la devoción popular (como el encuentro con los ladrones en la huida a Egipto) depurados ya en muchas Vitae Christi.

\section{OBSERVACIONES GENERALES}

Veintitrés textos en diferentes lenguas, sin contar los excluidos, muestran un interés manifiesto por la lectura de la vida de María, ya sea en un relato completo o parcial, con estructura típica o atípica, bien exento o bien inserto en una vida de Cristo. El éxito de esta lectura es tal que el género de las vidas de María acabará integrándose en los flores sanctorum postridentinos, como también se incluye la vida de Cristo. Los datos resultantes de la clasificación llevada a cabo pueden sintetizarse en el siguiente cuadro $^{79}$ :

\begin{tabular}{|c|c|c|c|c|}
\hline Obras peninsulares sobre la vida de María & Latín & Castellano & Portugués & Catalán \\
\hline Vidas de María anteriores a 1500 & 2 & 2 & 1 & 4 \\
\hline Vidas de María posteriores a 1500 & & 3 & & \\
\hline Textos afines anteriores a 1500 & & 5 & 1 & 3 \\
\hline Textos afines posteriores a 1500 & & 2 & & \\
\hline
\end{tabular}

Téngase en cuenta que en muchos casos las obras redactadas antes de 1500 fueron reeditadas varias veces en el siglo XVI, como ocurrió con la de Corella o singularmente con la de Peres. Cabe notar, entonces, que las obras catalanas se reimprimen en el XVI, pero no se producen nuevas vidas de María ni textos afines en catalán en esta centuria $^{80}$, mientras que sí encontramos dos de cada tipo en castellano, aparte de la traducción de la obra catalana de Peres. Por otro lado, la literatura catalana produce más

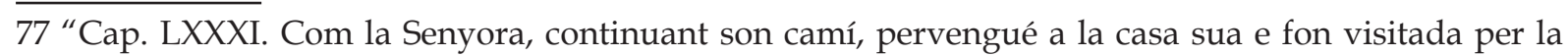
gloriosa santa Anna, sa mare"; "Cap. LXXXIII. Com la Mare de Déu pres comiat de la sua mare santa Anna ans que partís per a Egipte", etc.

78 "Cap. XC. Com la Senyora cridà lo seu espòs Josep que oís lo seu Fill, qui ja havia començat a parlat"; "Cap. XCIV. Com la Senyora teixia en un teler, lo qual havia fet Josep, e lo seu gloriós Fill li feia canons e la servia", etc.

79 Contamos también las traducciones, ya sean las que constituyen entrada independiente en el apartado de las Vitae Christi, ya sean las mencionadas al paso en los grupos anteriores.

80 Tras la fundación del Estudi General en la ciudad de Valencia en 1499, que contribuyó a la difusión del culto mariano, especialmente durante el rectorado del teólogo Joan de Celaya (1525-1558) (vid. Ferrer, 2003: 185-189), se escribieron muchos textos marianos, pero no otras vidas de María. 
vidas de María que textos afines, mientras ocurre lo contrario en el ámbito castellano. De estos datos puede extraerse la idea de que las obras catalanas son más genuinas en cuanto que contribuyen más a la conformación del paradigma de las vidas de María como género literario, sobre todo si se considera que en conjunto la producción castellana es mayor. Los dos testimonios portugueses reflejan una temprana actividad traductora de obras que vinculan la biografía de María a la de Cristo, en lo que coinciden con los dos textos latinos.

Podríamos observar que la creación de textos muestra una cierta focalización en algunos ámbitos de devoción mariana, entre los que destacan la corte alfonsí en el siglo XIII, y las ciudades de León y Valencia, a finales del XV y principios del XVI. De modo que, a excepción de las apuntadas versiones castellana y portuguesa de la obra de Brihuega, no hay continuidad entre la producción amparada por Alfonso X y la de los albores del Renacimiento.

El rey Sabio fue con toda probabilidad el más eminente cantor de la Virgen, y también, como queda dicho, un gran impulsor de obras ajenas a lo largo y ancho de su reino. Sin ir más allá de los datos mencionados aquí, contó con un colaborador en Zamora, Juan Gil, destacado erudito que estudió en París y participó del esplendor cultural que vivió Europa en aquel tiempo, y que llegó a ser preceptor del príncipe heredero; y Alfonso X tuvo otro colaborador en Sevilla, Bernardo de Brihuega, que recorrió todo el reino en búsqueda de material hagiográfico.

En la ciudad de León el culto a María podría haber resultado particularmente fértil, a juzgar por los testimonios de la obra de Juan Robles y del precedente que él mismo cita. Si pensamos en términos de reino y no de localidad, podríamos sumar además la obra de Juan López de Salamanca, también considerado de Zamora.

En los territorios de la corona de Aragón la devoción a la Virgen siempre estuvo muy arraigada, especialmente en lo relacionado con el inmaculismo, tan defendido por la clase gobernante como celebrado entre el pueblo. Las obras de eclesiásticos y literatos son prueba de ello, sobre todo en el contexto valenciano de finales del XV y primeras décadas del XVI, donde la devoción mariana constituyó fuente de inspiración para autores como Corella, Peres o Villena, o motivo de celebración en los certámenes poéticos.

Más allá de los contextos de creación, atendiendo a las características de las obras, observamos que las únicas vidas completas que presentan la estructura de ‘vida y milagros' son la de Gil de Zamora en latín, y la de Miquel Peres en catalán, ambas en prosa. No se puede afirmar que Peres conociera la obra de Juan Gil ${ }^{81}$, pero lo cierto es que muestran similitudes notables en el planteamiento: los dos se ocupan de los

81 Pese a la proximidad de la temática, no se aprecian dependencias significativas en la narración, y tampoco en los relatos de los milagros (Arronis, 2012: 174-176). Esto confirmaría el hiato entre las obras de época alfonsí y las de finales del Medievo. 
episodios litúrgicos, y además ambos los reordenan por orden cronológico, con lo que componen una verdadera vida de María; los dos beben de la tradición culta de los comentarios patrísticos que explican los pasajes canónicos y apócrifos, pero también ambos aligeran tanta doctrina y añaden el ingrediente más popular de los milagros. La obra de Gil de Zamora solo ha dejado un par de testimonios, pero su influencia pudo ser notable, si se considera que el escritor fue patrocinado por la corona. El éxito de la Vida de Peres sí que podemos constatarlo en las numerosas ediciones realizadas tanto en catalán como en castellano, y en las derivaciones de la obra; los inventarios, además, revelan la buena acogida entre los laicos ${ }^{82}$. Parece que la obra de Peres resolvió plenamente la carencia de una lectura sobre la vida de María, y que siguió sirviendo al público devoto durante más de medio siglo. Pero la Inquisición cortó esta trayectoria, pues el Índice de 1559, en la entrada 600, prohibía la difusión, reproducción o tenencia de "La vida de Nuestra Señora, en prosa y verso". Aunque sin precisar los autores, parece claro que Fernando de Valdés se refería a la Vida en prosa de Miquel Peres y a la versificación de esta de Francisco de Trasmiera. En el asiento 598 se prohíbe asimismo el Vergel de Nuestra Señora, la obra de Juan de Molina que se basa en buena medida en la de Peres $^{83}$. Se veta, por tanto, la lectura de relatos de la vida de María, pese a que, precisamente en las obras censuradas, no se aprecian elementos contrarios a la ortodoxia de la fe. No obstante, como ya apuntaba Bujanda (1984: 169-170), el Índice de Valdés, además de proscribir la heterodoxia, parece responder también a la preocupación por evitar los peligros que pudieran derivarse de la lectura individual. De este modo, se privó al público piadoso, pero acaso sencillo, de muchas obras devocionales difundidas durante décadas, como libros de horas, flores sanctorum o, como vemos, también vidas de María.

Sobre la intencionalidad de los textos, la voluntad de narrar la vida de María parece que se hace explícita solo a finales del siglo XV o inicios del XVI, pues únicamente cuatro obras presentan el título de "vida": el poema de Corella, la obra de Peres, la versificación de esta llevado a cabo por Trasmiera, y el texto de Juan de Robles sobre santa Ana y la Virgen niña. Otros títulos, aunque no de manera tan explícita, también expresan de algún modo la idea de peripecia o narración, como el caso del Libro de las historias de Nuestra Señora de López de Salamanca, o la breve Razón historial de Gómez

82 De hecho Peña (1997: 380), solo en la ciudad de Barcelona, encuentra la Vida de la sacratíssima verge Maria de Miquel Peres en once protocolos de bibliotecas privadas del siglo XVI, y concluye que no se puede apreciar una diferenciación por clases sociales, como es habitual en la literatura devocional, o, si acaso, que "la Vida de la Virgen parece interesar algo más a artesanos y mercaderes que a la nobleza. La distribución de los ejemplares por grupos sociales es la siguiente: tres artesanos, tres eclesiásticos, dos mercaderes, un ciudadano honrado y dos barceloneses de profesión desconocida" (Peña, 1997: 380).

83 Sin embargo, los estudios que se han referido a la cuestión siempre han identificado ambas entradas únicamente con el texto de Peres -véase por ejemplo Bujanda (1984: 550), Asensio (1988: 23) o Peña (1997: 380)-, sin apreciar, como ahora ponemos de manifiesto, que los asientos aluden a tres obras distintas. 


\section{García.}

En relación al público, cabe destacar el hecho de que muchos de estos textos, paradigmáticos o afines, están dedicados a mujeres, casi siempre de alta posición (es el caso de López de Salamanca, Miquel Peres, Juan de Robles, Juan de Molina). Por supuesto que estos libros también pudieron ser leídos por y ante hombres, pero parece claro que los autores apuntaban a un público femenino, damas, como las dedicatarias, pero también religiosas, burguesas, y finalmente todas las mujeres que pudieran ser sensibles a la contemplación, si no a la imitación, del más excelente de los modelos femeninos.

\section{Listado de obras excluidas}

Se trata en su mayoría de tratados mariológicos, colecciones de sermones sobre festividades marianas, o composiciones lírico-laudatorias. Aunque no son vidas de María, constituyen un testimonio escrito del culto mariano en la Península. Muchas de ellas abordan o aluden de alguna manera a los episodios terrenales de María, y por esto habían sido citadas como vidas por otros autores. Entre corchetes indicamos el origen de la noticia:

- Anónimo, Tractatus de nominibus beata Mariae Virginis [Rodríguez p. 186]

- Gonzalo de Berceo, Loores de Nuestra Señora [Rodríguez p. 186]

- Gonzalo de Berceo, Duelo de la Virgen [Rodríguez p. 186]

- Gonzalo de Berceo, Milagros de Nuestra Señora [Rodríguez p. 186]

- Alfonso X, Cantigas de Santa María [Rodríguez p. 186]

- Anónimo, Salve Regina, atribuida a Pedro de Mezonzo por algunos autores, [Rodríguez p. 186]

- $\quad$ Ramon Llull, Llibre del Ave Maria / Llibre de santa Maria [Bengoechea n 2, Rodríguez p. 187]

- Raimondo Ros, Llaor de santa María [Rodríguez p. 187]

- Juan Monzón, Místicas consideraciones del Rosario [Rodríguez p. 187]

- Gabriel Ferruç, Vers tractant de la salutació angélica [Rodríguez p. 187]

- Baltasar Balaguer, Respostes en lahor de la concepció [Rodríguez p. 187]

- Bernat Estrús, Cobles molt devotes a honor de nostre Senyor e de la sua beneyta Mare [Rodríguez p. 187]

- Fray Íñigo de Mendoza, Lamentación a la quinta angustia [Rodríguez p. 187] $]^{84}$

- Diego de San Pedro, Coplas de las siete angustias de Nuestra Señora (dentro del Tratado de Amores de Arnalte y Lucenda), 1491 [Rodríguez p. 187]

- Joan Roís de Corella, Tractat de la concepció de la sacratíssima verge Maria, ca. 1493, obra perdida

- Joan Roís de Corella, Contemplació a la sacratíssima verge Maria tenint son fill Jesús en la falda devallat de la Creu, Valencia, 1495 [Rodríguez p. 187]

- Bernat Fenollar et al., Trobes en lahors de la verge Maria, Valencia, 1474 [Rodríguez p. 187]

- Gaspar Gorricio de Novara, Contemplaciones sobre el Rosario de nuestra Señora historiadas, Sevilla, Ungut y Polono, 1495 [Gómez Redondo 2012 p. 919]

- Martín Martínez de Ampiés, Triunfo de María, Zaragoza, Pablo Hurus, 1495 [Rodríguez p. 187; Gómez Redondo 2012 p. 927] 
- Alonso de Fuentidueña, Título virginal de nuestra Señora, Pamplona, Arnao Guillén de Brocar, 1499 [Rodríguez p. 187; Gómez Redondo 2012 p. 959]

- Sancho Porta, Sermones festivitatum annualium Beatissimae Virginis Maria, Valencia, Joan Jofré, 1512,85 [Bengoechea $n^{\circ} 19$, Rodríguez p. 187]

- Andrés Gutiérrez de Cerezo, Paucissimi sudores in laudem virginis Mariae [Rodríguez p. 187]

- Tomás Real (Tomas Regio o Tomhe Regii), De virtutibus, gaudiis et doloribus Deiparae Virginis Mariae, 1533, obra perdida [Bengoechea $\mathrm{n}^{\circ} 20$ ]

- Tomás de Villanueva, Canciones nunc primum in lucem editae, Alacalá de Henares, Juan de Lequerica, $1572^{86}$ [Bengoechea $\mathrm{n}^{\mathrm{o}} 27$ ]

- Pedro de la Vega, Flos Sanctorum, 1521, 1534, 1540, 1569, 1572 [Bengoechea ${ }^{\circ}$ $25]^{87}$

- Baltasar Sorió, Mariale, 1538 [Bengoechea $n^{\circ}$ 23]

- Juan Bautista Agnés, Rosetum, 1545 [Bengoechea no 8]

- Flos sanctorum, Alcalá, Alonso Méndez de Robles, 1558 [Bengoechea no 14]

\section{BibLIOGRAFÍA}

Arenas Cruz, Elena (1999), “La teoría de los géneros y la historia literaria”, en Ricardo de la Fuente (ed.) (1999), La historia de la literatura y la crítica, Salamanca, Colegio de España: 159-188.

Arronis Llopis, Carme (2007), La vida de sancta Catherina de Sena de Miquel Peres, Alacant, Departament de Filologia Catalana.

Arronis Llopis, Carme (2010), "Els miracles marians en La vida de la Verge Maria de Miquel Peres (1494)", en José Manuel Fradejas Rueda et alii (eds.) (2010), Actas del XIII Congreso Internacional Asociación Hispánica de Literatura Medieval (Valladolid, 15 a 19 de septeimbre de 2009), Valladolid, Universidad de Valladolid: 389-406.

Arronis Llopis, Carme (2012a), La vida de la sacratíssima verge Maria de Miquel Peres: estudi i edició. Tesis doctoral, Alacant, Universitat d'Alacant.

Arronis Llopis, Carme (2012b), "Anàlisi de les vides de Maria de Miquel Peres i de Francisco de Trasmiera; repercussió de l'obra de Miquel Peres en la literatura castellana", en Rafael Alemany Ferrer y Francisco Chico Rico (eds.) (2012), Literatures ibèriques medievals comparades / Literaturas ibéricas medievales comparadas, Alacant, Selgyc/IIFV: 79-91.

Arronis Llopis, Carme (2013) "Juan de Molina, autor -y no traductor- del Vergel de Nuestra Señora", Studia Aurea.

Arronis Llopis, Carme (2014), “La tradición castellana de la Vida de la sacratíssima Verge

85 Aunque fue editada en 1512, esta colección de sermones sobres las festividades marianas es de la primera mitad del siglo XV.

86 Aunque los sermones fueron publicados tras su muerte, por fray Pedro de Uceda en 1572, fecha que excede el límite cronológico de este índice, su autor vivió en la primera mitad del siglo XVI (1486-1555), por lo que la obra sería anterior y quedaría enmarcada en nuestro límite temporal.

87 Bengoechea cita esta obra como una "Vita Mariae publicada en 1534", pero se trata en realidad de un flos sanctorum que contiene, como era de costumbre, las festividades marianas distribuidas a lo largo del año litúrgico, y no reunidas para componer una vida. 
Maria de Miquel Peres". Revista de Literatura Medieval, XXVI, 97-139.

Asensio, Eugenio (1988), "Censura inquisitorial de libros en los siglos XVI y XVII. Fluctuaciones. Decadencia", en M. Luisa López-Vidriero y Pedro Cátedra (eds.) (1988), El libro antiguo espanyol, I. Coleccionismo y Bibliotecas (s. XV-XVIII), Salamanca, Universidad de Salamanca, 21-36.

Baños Vallejo, Fernando (1989), La hagiografía como género literario en la Edad Media. Tipología de doce vidas individuales castellanas, Universidad de Oviedo.

Baños Vallejo, Fernando (2003), Las vidas de santos en la literatura medieval española, Madrid, Ediciones del Laberinto.

Baños Vallejo, Fernando (2009), "Para Isabel la Católica: la singularidad de un flos sanctorum (ms. h.II.18 de El Escorial)", en AA. DD. (2009), Los códices literarios de la Edad Media. Interpretación, historia, técnicas y catalogación, Salamanca, Instituto de Historia del Libro y de la Lectura: 161-193.

Baños Vallejo, Fernando (2012), "La transformación del flos sanctorum castellano en la imprenta", en Marinela Garcia Sempere y Ma Àngels Llorca Tonda (eds.) (2012), Vides medievals de sants: difusió, tradició i llegenda, Alicante, Institut Interuniversitari de Filologia Valenciana: 65-97.

Bautista, Francisco (2014), "Bernardo de Brihuega y la colección hagiográfica del ms. BNE 10252", Zeitschrift für romanische Philologie, 130, 1, 71-104.

Bautista, Francisco, "El rey y sus colaboradores", en Alfonso X El Sabio: http://www.cervantesvirtual.com/bib/bib_autor/alfonsoelsabio/ pcuartonivelc25d.html?conten=autor (consultado en febrero de 2014).

Bautista, Francisco (en prensa), "El final de la General estoria", Revista de Filología Española. Agradecemos al autor que nos haya adelantado copia de este estudio.

Bengoechea, Ismael (1984), "Catálogo español de Vidas de Nuestra Señora”, Scripta de Maria, 7, 559-600.

Berger, Philippe (1987), Libro y lectura en la València del Renacimiento, Valencia, Alfons el Magnànim.

Beyers, Rita (ed.) (1997), Libellus de Nativitate sancta Mariae. Textus et comentarius, en J. Gijsel y R. Beyers (eds.) (1997), Libri de Nativitate Mariae II, Turnhout, Brepols.

Bohdziewicz, Soledad (2012-2013), “El Liber Mariae de Juan Gil de Zamora. Hacia un estado de la cuestión”, Incipit, 32-33, 167-190.

Branco da Silva, Elsa Maria (2009), "Para uma leitura da parte primeira da tradução portuguesa da Vita Christi de Ludolfo, O Cartuxano", en Jesús Cañas Murillo, Francisco Javier Grande Quejigo y José Roso Díaz (eds.) (2009), Medievalismo en Extremadura. Estudios sobre Literatura y Cultura Hispánicas de la Edad Media, Cáceres, Universidad de Extremadura: 635-647.

Bujanda, J. M. (1984), Index des livres interdits, V. Index de l'Inquisition Espagnole. 1551, 1554, 1559, Quebec, Centre d'Études de la Renaissance / Éditions de l'Université de Sherbrooke.

Connolly, Jane (1990), Los miraglos de Santiago (Biblioteca Nacional de Madrid MS 10252), Universidad de Salamanca.

Deyermond, Alan (1990), “Lost Hagiography in Medieval Spanish: A Tentative Catalogue" en Alan D. Deyermond, Brian Dutton y Jane Connolly (eds.) (1990), Saints and their Authors: Studies in Medieval Hispanic Hagiography in Honor of John K. Walsh, Madison, Hispanic Seminary of Medieval Studies: 139-148.

Díaz y Díaz, Manuel (1962), “La obra de Bernardo de Brihuega, colaborador de Alfonso X", Acta Salmanticensia, 16, 145-161.

Escartí, Vicent J. (2011), Vita Christi. Isabel de Villena, Valencia, Edicions Alfons el 
Magnànim.

Ferrando Francés, Antoni (1983), Els certàmens poètics valencians, Valencia, Edicions Alfons el Magnànim.

Ferrando Francés, Antoni (1993), "Sobre una etiqueta historiogràfica de la literatura catalana", Caplletra, 15, 11-30.

Ferrer Romaguera, Manuel (2003), Ortodoxia y humanisme. El Estudio General de Valencia durante el rectorado de Joan de Salaya (1525-1558), Valencia, Universitat de València.

Ferrero Hernández, Cándida (2010) "Nuevas perspectivas sobre Juan Gil de Zamora", Studia Zamorensia, 9, 19-33.

Fidalgo, Elvira (2005), "Sobre las fuentes de los Miraglos de Santiago”, Bulletin of Hispanic Studies, 82, 3, 293-312.

Fita, Fidel (1885a), "Poesías inéditas de Gil de Zamora", Boletín de la Real Academia de la Historia, 6, 380-410.

Fita, Fidel (ed.) (1885b), "Cincuenta leyendas por Gil de Zamora combinadas con las cantigas de Alfonso el Sabio", Boletín de la Real Academia de la Historia, 7, 54-144.

Fradejas Lebrero, José (1993a), "La Visión de san Pablo", Revista de Filología Española, 73, 3/4, 391-397.

Fradejas Lebrero, José (ed.) (1993b), San Bernardo, Abad de Caravaca, Miraglos de Nuestra Señora, Madrid, Tipographia Unypressiana, edición no venal.

Furió, Joan Maria (2013), "Allò que Corella ha "corregit, smenat y ben examinat" en el Cartoixà. Contribució a l'estudi de la traducció a partir del Terç», Afers, XXVIII (76), 687-715.

Gallardo, Bartolomé José (1889), Ensayo de una biblioteca española de libros raros y curiosos IV, Madrid, Manuel Tello.

García, Gómez (1988 [1500]), Carro de dos vidas, ed. de Melquiades Andrés Martín, Madrid, Universidad Pontificia de Salamanca/Fundación Universitaria Española.

García Berrio, Antonio, y Javier Huerta Calvo (1992), Los géneros literarios: sistema e historia, Madrid, Cátedra.

Garrido Gallardo, Miguel Ángel (1988), Teoría de los géneros literarios, Madrid, Arco.

Genicot, Léopold (1972), Introduction. Typologie des sources du Moyen Age occidental I, Turnhout, Brepols.

Gómez Redondo, Fernando (2007), Historia de la prosa medieval castellana IV, Madrid, Cátedra.

Gómez Redondo, Fernando (2012), Historia de la prosa de los Reyes Católicos: el umbral del renacimiento $I$, Madrid, Cátedra.

González Cuenca, Joaquín (ed.) (2004), Hernando del Castillo, Cancionero General I, Madrid, Castalia.

Hauf, Albert (1978), “La Vita Christi de Fr. Francesc Eiximenis, O.F.M. (1340?-1409) como tratado de Cristología para seglares", Archivum Franciscanum Historicum, 71, 37-64.

Hauf, Albert (1995), Isabel de Villena, Vita Christi (selecció), Barcelona, Ed. 62.

Hauf, Albert (2001), "Fray Hernando de Talavera, O.S.H., y les traduccions castellanes de la Vita Christi de Fr. Francesc Eiximenis, O.F.M.", en Tomás Martínez y Roxana Recio (eds.) (2001), Essays on Medieval Translation in the Iberian Peninsula, Castellón/ Omaha: Universitat Jaume I/Creighton University: 203-250.

Jauss, Hans-Robert (1970), "Littérature médiévale et théorie des genres", Poétique, 1, 79-99.

Jauss, Hans-Robert (1979), "The Alterity and Modernity of Medieval Literature", New Literary History, X, 2, 181-229, traducción de Alterität und Modernität der 
mittelalterlichen Literatur, Munich, W. Fink Verlag, 1977.

Jiménez Moreno, Arturo (ed.) (2009), Libro de las historias de Nuestra Señora de Juan López de Salamanca. Edición y estudio, San Millán de la Cogolla, Cilengua.

Marsá Vilá, María (2007), Materiales para una historia de la imprenta en Valladolid (siglos XVI y XVII), Universidad de León.

Martos, Josep Lluís (2013), "Variantes y variaciones interpoemáticas: de La vida de la sacratíssima verge Maria a la Lahor de la Verge de Joan Roís de Corella", Revista de Literatura Medieval, 25, 135-164.

Miquel i Planas, Ramon (1913), Obres de Joan Roís de Corella, Barcelona, Giró.

Pego Puigbó, Armando (2004), El Renacimiento espiritual. Introducción literaria a los tratados de oración españoles (1520-1566), Madrid, CSIC.

Peña Díaz, Manuel (1997), El laberinto de los libros. Historia cultural de la Barcelona del Quinientos, Madrid, Fundación Germán Sánchez Ruipérez.

Pérez García, Rafael (2006), La imprenta y la literatura espiritual castellana en la España del Renacimiento, 1470-1560, Gijón, Ediciones Trea.

Ribadeneira, Pedro de (1716 [1599]), «Vida de la gloriosa Virgen María nuestra señora», Flos Sanctorum I, Madrid, Rodríguez Escobar, 146-168.

Riquer, Martí de (1964), Història de la Literatura Catalana, III, Barcelona, Ariel.

Rodríguez, Isaías (1967), "Autores espirituales españoles en la Edad Media”, en AA. DD. (1967), Repertorio de historia de las ciencias eclesiásticas en España I, Salamanca, Instituto de Historia de la Teología Española: 175- 351.

Rodríguez Pequeño, Francisco Javier (1995), Ficción y géneros literarios, Universidad Autónoma de Madrid.

Sanchis Guarner, Manuel (1979), Les trobes en lahors de la Verge Maria, Valencia, Vicent García Editors S. A.

Segura, Antonio y Vallejo, Pilar (2003), Catálogo de los impresos del siglo XVI de la Biblioteca Colombina de Sevilla III, Cabildo de la S.M. y P.I. de la Catedral de Sevilla, Institución Colombina.

Simón Díaz, José (1985), Mil biografías de los Siglos de Oro (Índice bibliográfico), Madrid, CSIC, 17-19.

Vílchez, María Rosa (2007), “A manera de introducción”, en F. Rodríguez (ed.) (2007), Juan Gil de Zamora, Milagros de santa María del Liber Mariae, Zamora, Semuret: $17-49$. 